\title{
De la Protohistoria a la Historia en Menorca. Arquitectura y organización espacial en Son Catlar (Ciutadella, Menorca)*
}

\author{
From Protohistory to History in Minorca. Architecture and \\ spatial organization in Son Catlar (Ciutadella, Minorca)
}

\author{
Helena Jiménez Vialás \\ Universidad de Murcia, Grupo de investigación E041-04 \\ Centro de Estudios del Próximo Oriente y la Antigüedad Tardía \\ vialas@um.es \\ ORCID iD: https://orcid.org/0000-0002-9679-6968 \\ Octavio Torres Gomariz \\ Universidad de Alicante \\ octavio.torres@ua.es \\ ORCID iD: https://orcid.org/0000-0002-1933-5551
}

Enviado: 04-07-2020. Aceptado: 16-12-2020. Publicado online: 05-10-2021

Cómo citar este artículo / Citation: Jiménez Vialás, H. y Torres Gomariz, O. (2021). "De la Protohistoria a la Historia en Menorca. Arquitectura y organización espacial en Son Catlar (Ciutadella, Menorca)". Archivo Español de Arqueología, 94, e17. DOI: https://doi.org/10.3989/aespa.094.021.17

RESUMEN: El poblado de Son Catlar (Ciutadella, Menorca), con sus cinco talayots y su muralla extraordinariamente conservada a lo largo de casi $1 \mathrm{~km}$ de perímetro, es uno de los principales núcleos de la Menorca protohistórica y romana. Presentamos en este texto un amplio volumen de datos inéditos, resultado de recientes trabajos de prospección intensiva y estudio arquitectónico, que ilustran sobre la organización espacial de las fases talayótica, postalayótica -incluyendo una refortificación asociada a la segunda guerra púnica- y romana. La entidad del poblado y su ocupación aparentemente ininterrumpida a lo largo de este amplio periodo, lo convierten en un ejemplo excepcional a la hora de estudiar la particular evolución de las comunidades baleáricas a lo largo de la Edad del Hierro y en época romana.

Palabras clave: Talayótico; postalayótico; romano; prospección intensiva; Islas Baleares.

ABSTRACT: Son Catlar, with five talayots and an extraordinarily preserved city wall of almost $1 \mathrm{~km}$ of perimeter, is one of the main sites of Protohistoric and Roman Minorca. A big volume of new data issued from recent intensive survey and architectural study is presented in this paper. It illustrates about the spatial organization along Talayotic, Post-Talayotic (including a refortification related to the second Punic war) and Roman periods. The relevance of the site and the fact that it was occupied throughout this extended period, make it an optimal case study to approach the particular evolution of Balearic communities throughout the Iron Age and in Roman times.

\footnotetext{
* Este trabajo recoge resultados científicos y de transferencia del conocimiento del Proyecto Modular: arquitectura fenicio-púnica de Menorca, financiado por el Consell Insular de Menorca.
} 
Keywords: Talayotic; Post-Talayotic; Roman; intensive survey; Balearic Islands.

Copyright: (C) 2021 CSIC. Este es un artículo de acceso abierto distribuido bajo los términos de la licencia de uso y distribución Creative Commons Reconocimiento 4.0 Internacional (CC BY 4.0).

\section{SON CATLAR EN LA PROTOHISTORIA ${ }^{1}$ Y LA ANTIGÜEDAD DE MENORCA}

Son Catlar (Ciutadella) es uno de los yacimientos arqueológicos más espectaculares de Menorca. Aunque sus orígenes se remontan a la Edad del Bronce, fue en el primer milenio a. C. y en especial en los siglos en torno a la Era cuando alcanzó su máximo desarrollo, durante las fases talayótica, postalayótica y romana.

$\mathrm{Su}$ principal característica es la imponente muralla -de hasta $6 \mathrm{~m}$ de ancho en algunos puntos y con alzados conservados en más de $3 \mathrm{~m}$ - que enmarca sus 4,4 ha de superficie y se conserva casi íntegra a lo largo de 900

1 La periodización y terminología de la arqueología balear ha sido siempre objeto de controversia: para las Gimnesias es habitual el término "Prehistoria" desde la primera ocupación humana hasta la conquista romana, empleándose de forma muy reciente "Protohistoria" para su fase final. La diferencia principal entre ambos términos es la concepción monolítica o no de las culturas que se desarrollaron desde finales del segundo y a lo largo del primer milenio a. C.: "Talayótico Final" (Rosselló-Bordoy, 1972; Plantalamor, 1991) en una concepción más continuista, en contraposición a "Postalayótico" (Rosselló-Bordoy, 1963; Guerrero, 1997) o "Balear" (Hernández-Gasch, 2009). $\mathrm{m}$ de perímetro (Fig. 1). El interior del poblado, sin embargo, ha suscitado una menor atención por parte de los investigadores, por lo que solo contamos hoy con varios planos muy esquemáticos que apenas recogen los talayots y la taula -construcciones emblemáticas de la Protohistoria de Menorca ${ }^{2}$ - (Pericot, memoria inédita ${ }^{3}$; Plantalamor, 1991, lám. I; De Nicolás, 1995).

El panorama es similar en otros yacimientos de la isla y se caracteriza por un magnífico estado de conservación de las estructuras arqueológicas, fácilmente visibles la mayoría de las veces, aunque edificaciones rurales modernas y la densa vegetación dificultan con frecuencia acceder a las mismas.

Desde el año 2014, el "Proyecto Modular: arquitectura fenicio-púnica” ha venido trabajando en Menorca

2 La singularidad de estas estructuras las ha convertido en elemento definitorio para la periodización: talayots en la primera Edad del Hierro y taulas en la segunda (Guerrero, Calvo y Gornés, 2006); estas últimas corresponden a la parte central de los santuarios (también conocidos en la bibliografía como "recintos"), por lo que así nos referiremos a ellas en el texto.

3 Pericot, L. (1958). La cultura prehistórica balear. Memoria inédita depositada en la Fundación Juan March, disponible en la biblioteca de esta institución (signatura MB-1958.7).

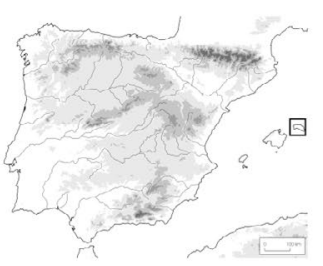

MENORCA

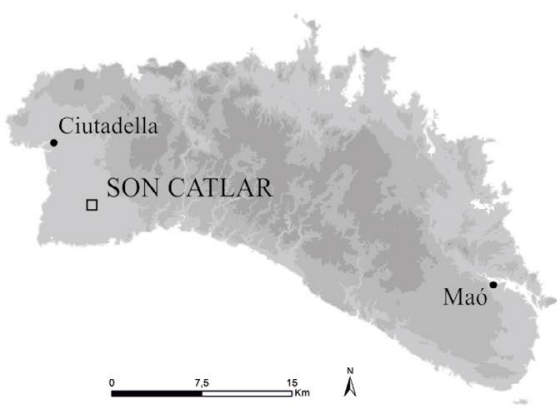

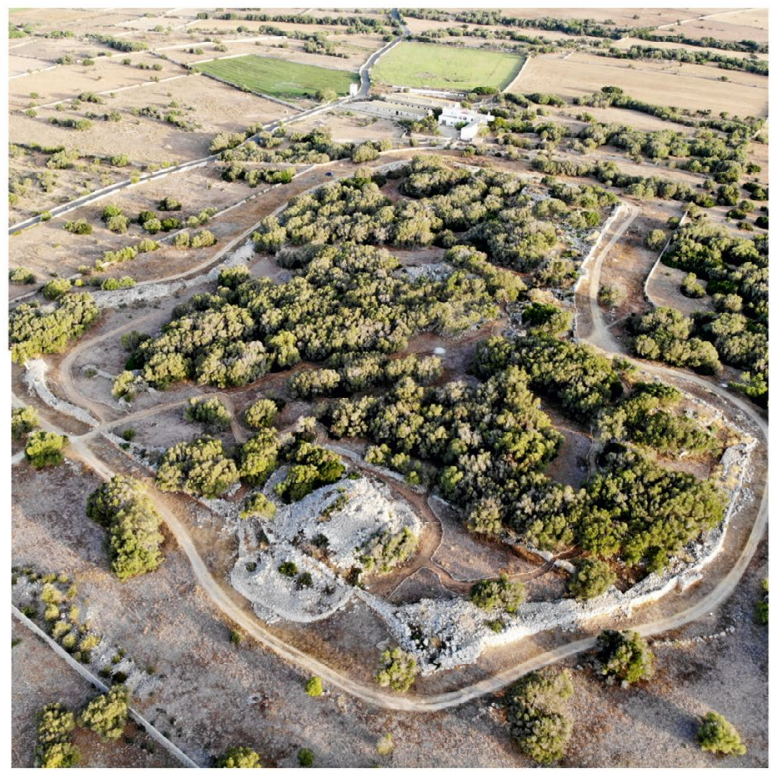

Figura 1. Ubicación de Son Catlar e imagen aérea donde se aprecia el grado de conservación del encintado (C) Proyecto Modular 2020). 


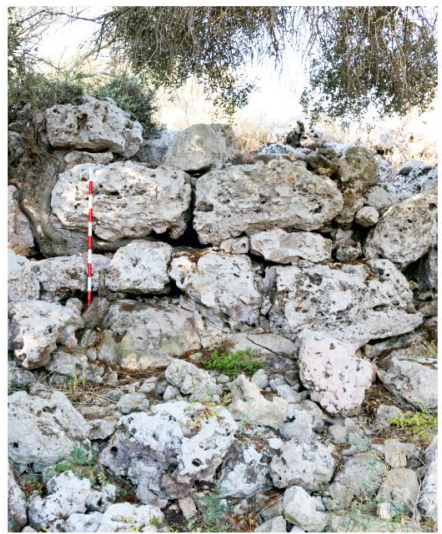

Talayot 4

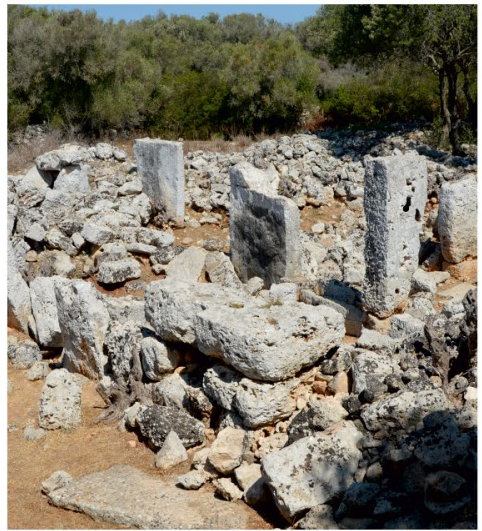

Santuario de taula

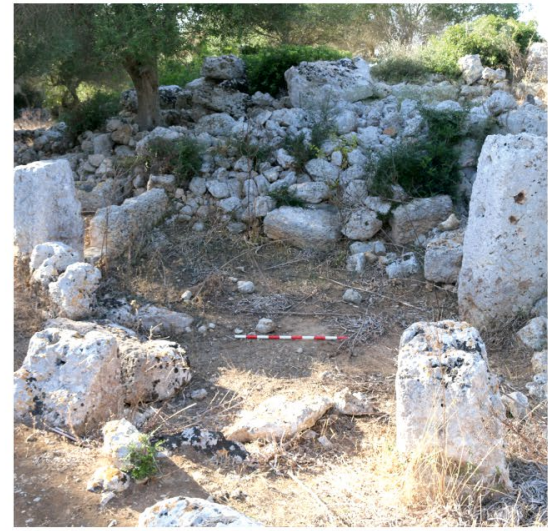

Cercle

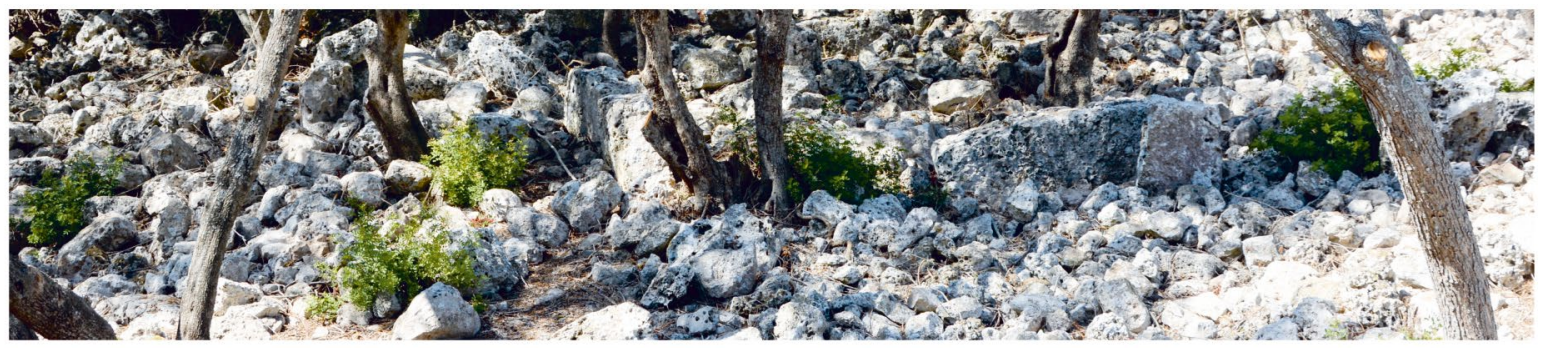

Figura 2. Algunas estructuras visibles hoy en el poblado y aspecto general de la superficie prospectada (C) Proyecto Modular 2018).

a fin de caracterizar las respuestas locales al impacto de la cultura fenicio-púnica (Prados et al., 2015). En Son Catlar, las recientes excavaciones arqueológicas parecen confirmar que la refortificación de la muralla preexistente con bastiones y otras soluciones defensivas complejas se sitúa entre los siglos III y II a. C., vinculada al horizonte bélico romano-cartaginés (Prados et al., 2017a y 2020). Asimismo, se apreciaban en el poblado muros de tendencia circular y diferentes materiales que remitían a las fases talayótica y postalayótica, así como posibles estructuras cuadrangulares. Por todo ello, se hizo evidente la necesidad de una prospección sistemática con el objetivo de registrar todas las estructuras visibles, tratando de identificarlas en función de las características conocidas para las diversas manifestaciones arquitectónicas de la Protohistoria menorquina, lo que nos ha permitido proponer, por vez primera, una secuencia histórica del poblado (Fig. 2).

\section{INVESTIGACIONES PREVIAS EN SON CATLAR}

Son Catlar aparece ya citada en obras de referencia para la historiografía menorquina como las Antigüedades célticas de Joan Ramis y Ramis (1818) o la Historia de la isla de Menorca de Rafael Óleo y Quadrado (1874). La primera actuación de la que tenemos cons- tancia fue llevada a cabo por el prehistoriador francés Émile Cartailhac (1892) en el santuario de taula. En este mismo lugar excavó en el año 1923 Francesc Hernández Sanz, y aunque los resultados nunca fueron publicados en su totalidad (Hernández Mora, 1948, p. 297), disponemos de breves noticias sobre la cerámica (Martínez Santa-Olalla, 1924) o la inscripción latina recuperadas en el recinto (Mayer, 2005, pp. 44-45). En este contexto encontramos los primeros intentos de trazar un plano del yacimiento (Vives Escudero, 1908, p. 1053; Hernández Mora, 1923, p. 27).

En 1958, un equipo dirigido por Lluís Pericot obtuvo financiación de la Fundación March para estudiar la Prehistoria del archipiélago balear. Aunque la monografía resultante no vio la luz hasta años después (Pericot, 1975), diversos artículos firmados generalmente por M. L. Serra (1961, 1963, 1967), así como el preceptivo informe administrativo (Pericot, memoria inédita), ilustran sobre estas intervenciones. Realizaron la primera planimetría general del yacimiento (recogida en Jiménez Vialás et al., 2019, fig. 5.3), que representa con cierto detalle las estructuras visibles, en especial las viviendas circulares -llamadas cercles-(Serra, 1965).

No será hasta 1987 cuando se retome la actividad en el poblado. En este caso el Museu de Menorca, junto al Consell Insular de Menorca y el Ajuntament de Ciutadella, acometieron una serie de actuaciones para 

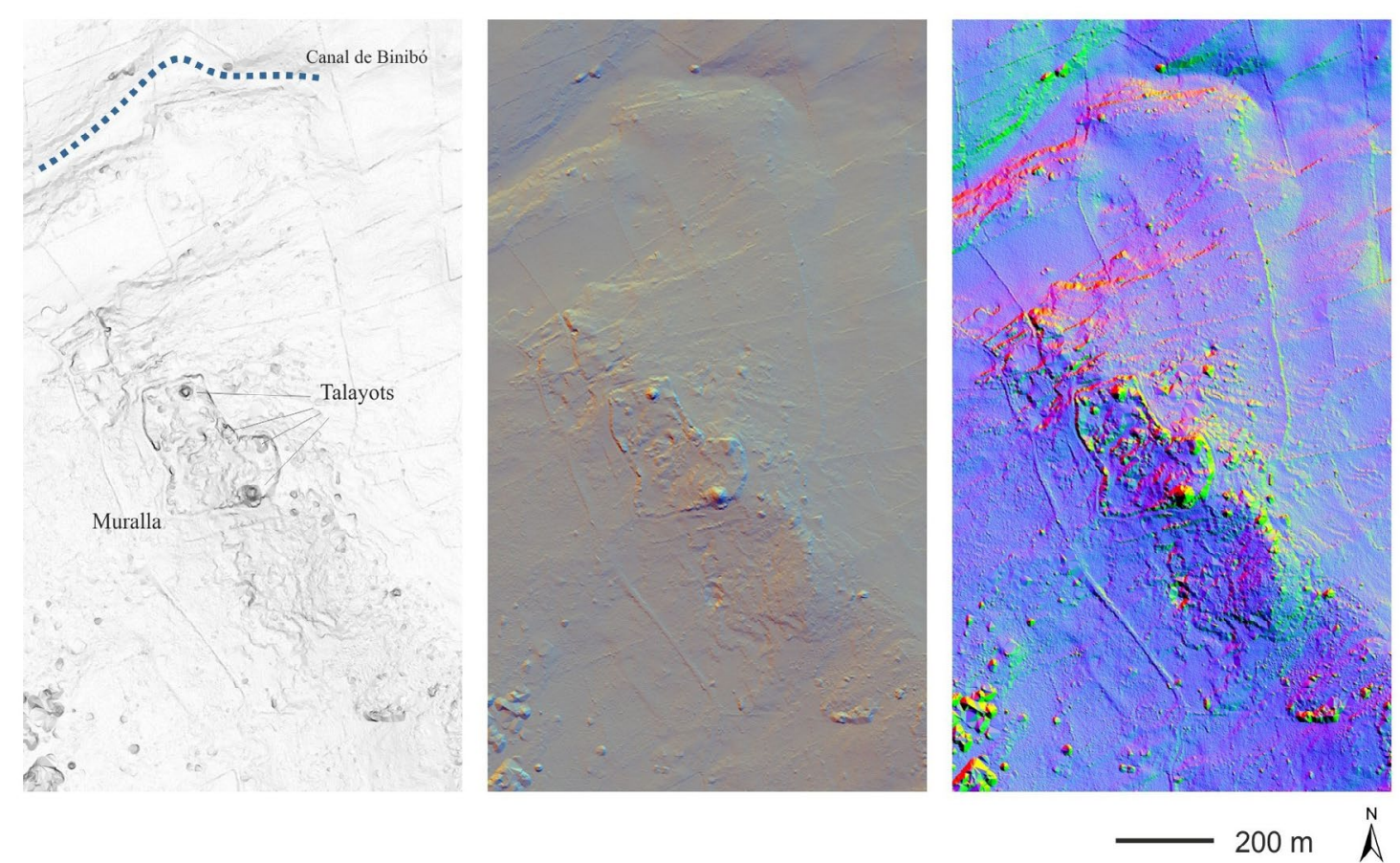

Figura 3. En el MDT de alta resolución se aprecia con claridad la elevación donde se erigió el poblado, el canal de Binibó al norte, así como la prominencia del encintado y los talayots en el relieve circundante (visualizaciones Relief Visualization Tool).

la conservación y puesta en valor (Juan, Pons y Juan, 1998, p. 7). En 1995 el Consell editó un tríptico donde se incluía una planimetría esquemática (De Nicolás, 1995) y tras la excavación de la llamada "puerta norte", se realizaron itinerarios con cartelería específica (Juan, Pons y Juan, 1998); en ambos casos se recogen los elementos ya señalados -talayots y santuario de taula- sin apenas otras evidencias. En la actualidad, Son Catlar atraviesa un buen momento. Ha sido recientemente adquirido por el citado Consell y se ha elaborado un Plan Director que marca las líneas de investigación, conservación y puesta en valor a desarrollar en los próximos años (Jiménez Vialás et al., 2019).

\section{ANÁLISIS ESPACIAL PARA UNA LECTURA SOCIAL}

\subsection{Son Catlar en su paisaje}

En nuestra aproximación al poblado de Son Catlar es necesario tener en consideración, aunque sea de forma breve y superficial, aspectos relativos a su emplazamiento y la relación con el medio en que se inserta. Otros aspectos más difíciles de analizar desde el registro arqueológico, pero esenciales para poder entender la dimensión espacial de una cultura, como la percepción y conceptualización del espacio, o el papel de las prácticas y la memoria social (Criado, 1993; Ingold, 1993; Tilley, 1994; Thomas, 2001), han sido igualmente tenidos en cuenta a la hora de analizar los comportamientos espaciales en cada uno de los periodos analizados, a nivel tanto de poblado como de territorio. Hemos de tener en cuenta además que los estudios de paisaje son una línea de investigación poco explorada hasta ahora en la isla ${ }^{4}$, tal y como ha señalado el informe de ICOMOS a la candidatura de la Menorca Talayótica a la Lista de Patrimonio Mundial de la UNESCO (2017).

El poblado de Son Catlar se sitúa en el cuadrante SO de Menorca, a $6 \mathrm{~km}$ de Ciutadella, principal puerto y núcleo urbano de la mitad occidental de la isla. Esta zona se enmarca en la gran plataforma miocena que conforma el mediodía insular y que se eleva sobre el mar, formando acantilados o pequeños arenales allá donde los barrancos han abierto brechas en la roca a lo largo de milenios. Esta planicie de suelo calcáreo es una de las zonas más aptas agrícolamente, tanto históricamente como en la actualidad. Además, en una isla donde la preocupación por el agua ha condicionado las pautas de poblamiento desde la Prehistoria, Son Catlar dispone de una charca temporal a poco más de $1 \mathrm{~km}$, un recurso hídrico fundamental (Fe-

4 Son contados los estudios que abordan el territorio menorquín desde una perspectiva de paisaje: De Álvaro, 1983; Juan, 1993; Gornés et al., 2004 o De Cet, 2017, entre algunos otros. 


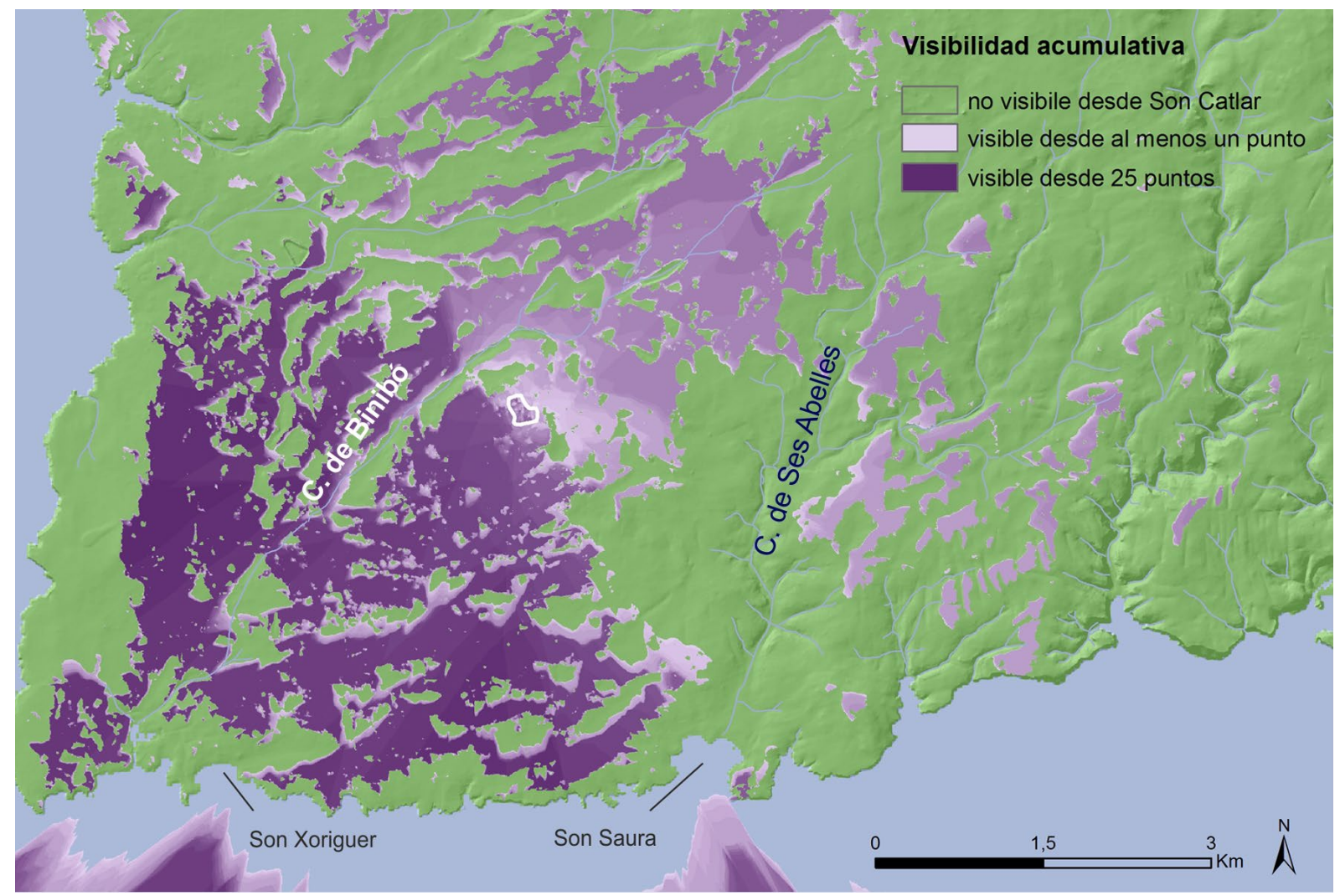

Figura 4. Mapa de visibilidad acumulativa desde el poblado (@ Proyecto Modular 2020).

rrer, 2010). Cuenta también con la cercanía de torrentes que comunican con el mar, al situarse entre los canales de Binibó y de ses Abelles, en lo que resulta ser uno de los interfluvios más amplios de la isla, una extensión relativamente plana en el fragmentado relieve menorquín, que conforma en nuestra opinión una verdadera unidad de paisaje, bien delimitada, en torno a Son Catlar.

Nuestro análisis se ha apoyado en un Sistema de Información Geográfica (SIG), herramienta de utilidad demostrada para los estudios de paisaje (Grau, 2006), que ha permitido recopilar una variada información de tipo geográfico e integrar los elementos arqueológicos observados en el campo con su ubicación precisa. El estudio topográfico se ha basado en modelos digitales del terreno (MDT) con una resolución de entre 5 y 0,5 $\mathrm{m}$ (este último basado en tecnología $\operatorname{LiDAR}^{5}$ ), a partir de los cuales hemos efectuado una serie de visualizaciones y análisis de interés arqueológico (pendiente, orientación, visibilidad, etc.).

5 Plan Nacional de Ortofotografía Aérea (PNOA) de 2014-2015, densidad media de 0,5 puntos por $\mathrm{m}^{2}$. Documentación facilitada por el Centro Nacional de Información Geográfica (CNIG): https://pnoa.ign.es/caracteristicas-tecnicas
El punto escogido para instalar el poblado fue una loma con una altitud media de $40 \mathrm{~m} \mathrm{~s}$. n. m. y unos $2 \mathrm{~km}$ de longitud en sentido NO-SE que marca un cambio de orientación del terreno: mientras que en las tierras situadas al SE y formadas por campos de cultivo predomina una orientación sur y suroeste (hacia el mar), al NE prevalece la orientación norte y noreste con tierras más agrestes donde se conservan zonas de encinar original, que conectan con las cabeceras de los mencionados torrentes. En el MDT de alta resolución apreciamos cómo tanto los talayots como la muralla aprovechan esta elevación para su erección, ganando altura sobre el entorno y a la vez beneficiándose de las dos orientaciones señaladas (Fig. 3). Resulta claro por tanto que ya desde el inicio de la ocupación del lugar hubo un interés por aprovechar los territorios productivos al sur, sin descuidar el control hacia el interior y la cabecera de los torrentes. El poblado disfrutaba además de una amplia visibilidad sobre su entorno, en especial hacia el suroeste y el mar en dirección a Mallorca-visible la mayoría de los días- aunque, llamativamente, no sobre amplias zonas de la costa oeste; de hecho, la comunicación visual es mejor con playas del sur como Cala en Bosc / Son Xoriguer o Son Saura (Fig. 4). 
Además de los aspectos geográficos y topográficos mencionados, hay dos elementos que resultan fundamentales para entender tanto la ubicación del poblado como su organización: el agua y la piedra. En la esquina suroeste del recinto existe una gran higuera que ha alterado la estructura de lo que parece un pozo o una cueva funeraria que por su naturaleza subterránea acumula agua hasta convertirse, como en tantos otros lugares de la isla, en una cisterna. El hecho de que este punto se incluya de forma intencionada en el poblado, siendo el único ángulo de la muralla que no viene definido por la presencia de un talayot, parece reflejar la importancia funcional y también simbólica de este pozo.

En lo que respecta a la piedra, principal material de construcción de la isla, ya se conocían algunas canteras en el entorno de Son Catlar (Serra, 1963, p. 191; Kopper y Rosselló-Bordoy, 1974, p. 165) y hemos podido constatar varias zonas de extracción también en el interior del poblado. Si bien el nivel de arrasamiento de la mitad meridional dificulta valorar su contexto, es posible que fueran empleadas -con posterioridad a la extracción- para la erección de viviendas, tal y como se ha documentado en Torre d'en Galmés (Pérez-Juez y Goldberg, 2018).

\subsection{Prospección INTRAMURos: LA ARQUitectura COMO REFERENCIA}

Como ya hemos mencionado, la técnica empleada para elaborar un plano general de las estructuras visibles fue la prospección intensiva que, si bien tiene las lógicas limitaciones inherentes al conocimiento superficial, ha demostrado una gran eficacia a la hora de identificar yacimientos o usos del suelo en diferentes contextos (Mayoral, Cerrillo y Celestino, 2009; Grau et al., 2012). El reconocimiento del terreno estuvo asistido por labores de fotointerpretación y dada la dificultad técnica que planteaba la densa vegetación para el manejo del equipo topográfico, la toma de datos se realizó con receptores GPS de mano, de fácil manipulación en este contexto y con una precisión suficiente (error inferior a $3 \mathrm{~m}$ ), lo que permitió la cobertura total del yacimiento en una sola campaña.

Nuestra actuación ha tenido sin embargo una particularidad importante: la unidad de trabajo han sido las estructuras y no la cerámica. El motivo ha sido doble: por un lado, como hemos podido comprobar en diferentes yacimientos de la isla, la superficie está tremendamente alterada debido a la recogida de fragmentos cerámicos por parte de los visitantes (Jiménez Vialás et al., 2017); por otro, la envergadura de los restos y el hecho de que para los periodos talayótico y postalayótico sus construcciones resulten absolutamente definitorias, hacían idónea una prospección basada en la arquitectura (Fig. 5). Si bien es cierto que los restos constructivos no aportan información cronológica tan precisa como la cerámica, ofrecen sin embargo valiosos datos sobre los diferentes usos sociales del espacio, la caracterización cultural y la secuencia histórica (Gutiérrez y Grau, 2013). Con estos objetivos en mente, y basándonos tanto en publicaciones existentes (Hernández Mora, 1948; Serra, 1961; Mascaró, 1982; Plantalamor, 1991; Juan, Pons y Juan, 1998) como en nuestros trabajos previos en yacimientos menorquines, hemos establecido la existencia de tres grandes fases cronoculturales: talayótica, postalayótica y romana (Tab. 1).

De cada conjunto en que dividimos el yacimiento, tomamos información espacial detallada mediante puntos o nubes de puntos de GPS: perímetro, estructuras, materiales singulares, etc.; asimismo, añadimos una completa información descriptiva, asistida con una nutrida documentación fotográfica y croquis. Aunque no hubo recogida de cerámica por los motivos indicados, sí tuvimos en cuenta el escaso material observado, en función del tipo de producciones, la coherencia o no de su adscripción en relación con las estructuras cercanas, mediante descripciones genéricas y georreferenciando aquellos elementos más destacados por su carácter diagnóstico. Posteriormente procedimos a la integración de los datos en el SIG, donde sobre la base de una ortofotografía de alta resolución tomada con un dron, hemos representado de forma esquemática cada una las estructuras identificadas, confeccionando así la primera cartografía arqueológica de Son Catlar en sus diferentes fases.

\section{DISCUSIÓN DE LOS RESULTADOS: ORIGEN Y EVOLUCIÓN HISTÓRICA DEL POBLADO}

\author{
4.1. Fase talayótica (aprox. XI-VI a. C.): \\ LA GÉNESIS DEL POBLADO
}

Aunque algunos fragmentos cerámicos recuperados y la existencia de tres cuevas funerarias del periodo naviforme en las inmediaciones apuntarían a una ocupación previa (Plantalamor y Rita, 1982), es la fase talayótica, correspondiente al Bronce Final y Hierro I, la que marca el inicio del poblamiento en el lugar. Los talayots que le dan nombre se encuentran tanto en Mallorca como en Menorca, y son grandes torres erigidas con inmensos bloques horizontales de piedra; los ejemplos mallorquines presentan plantas circulares o cuadrangulares, con cámaras y pilares centrales, mientras que los menorquines son de mayor tamaño y tienden a formas generalmente redondeadas. Su sig- 
TALAYÓTICO

Talatí de Dalt

Cornia Nou
Talayot

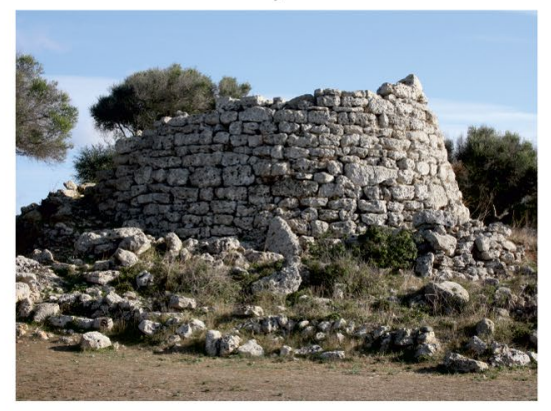

Talayot y edificio anexo

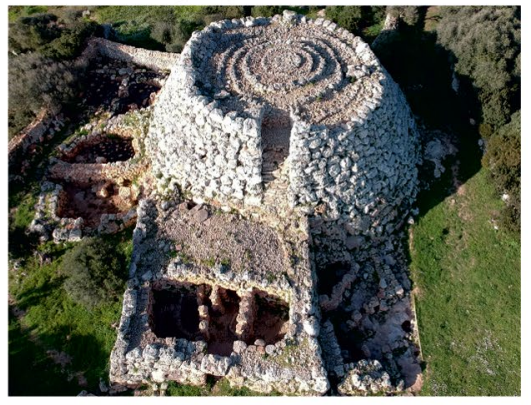

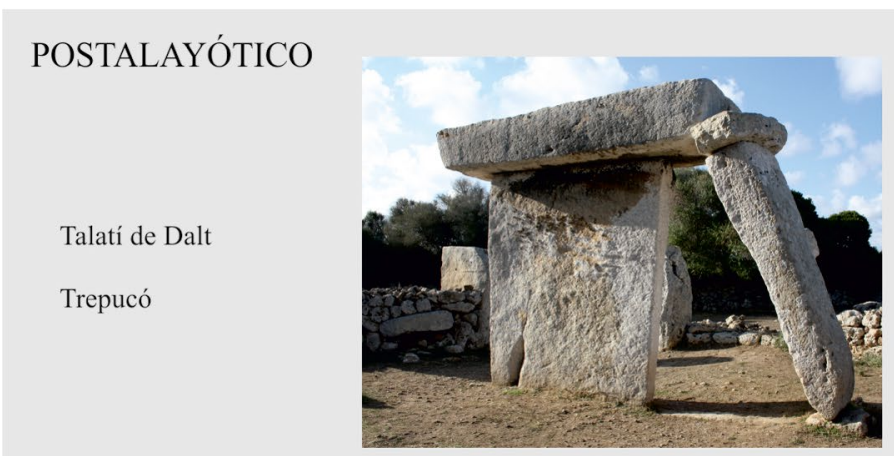

Santuario de taula

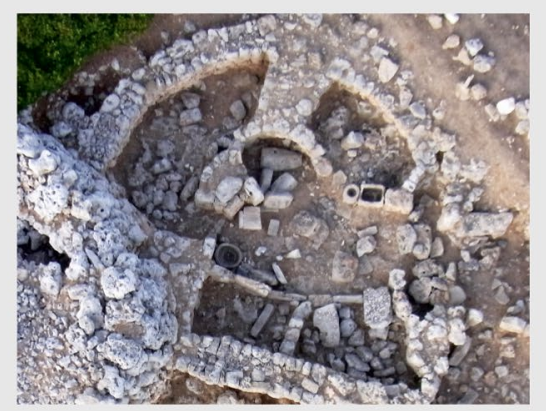

Vivienda (cercle)

Figura 5. Construcciones representativas de los periodos talayótico y postalayótico (C Equip Cornia 2019; Proyecto Modular 2013-2014).

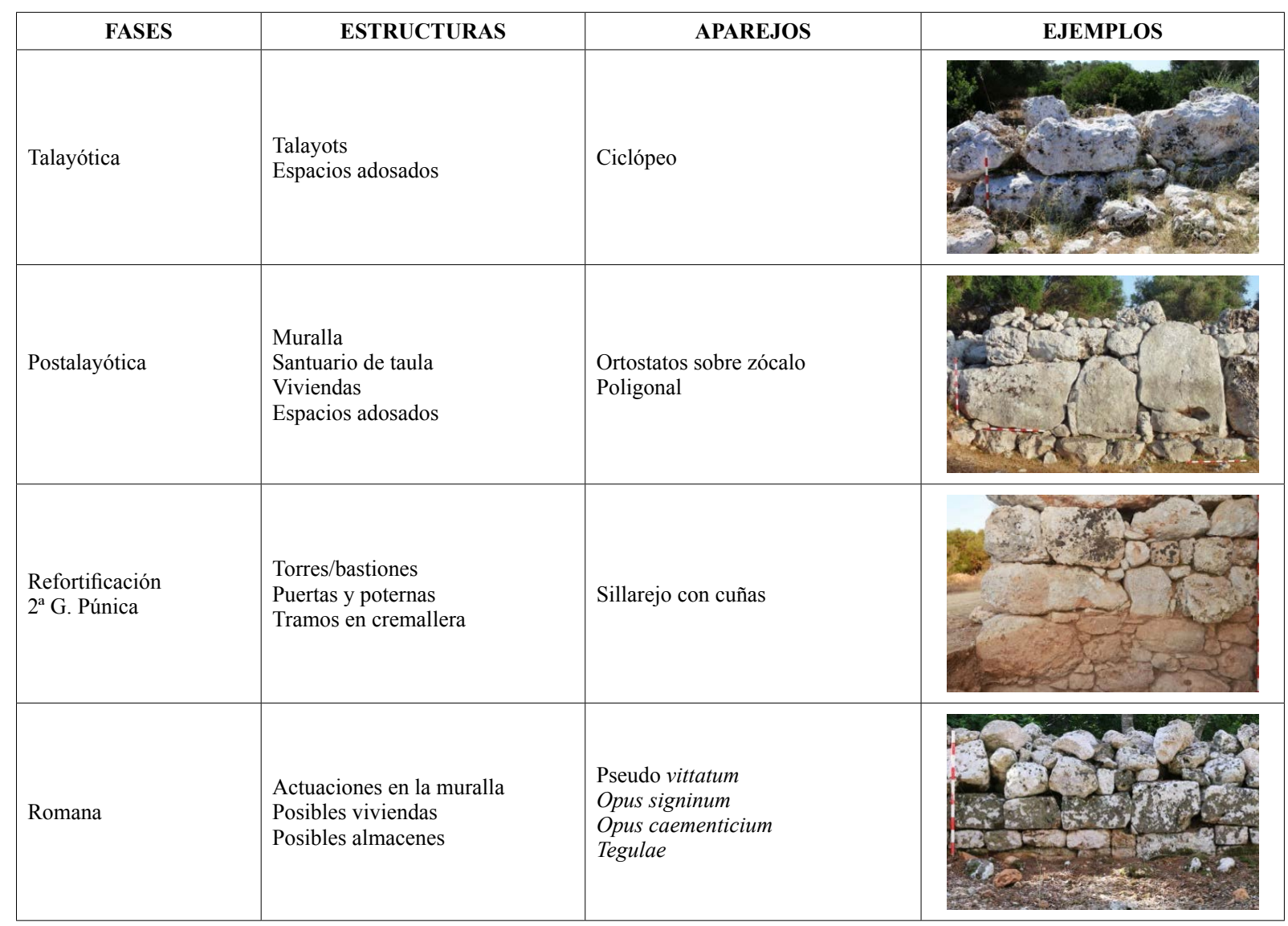

Tabla 1. Caracterización arquitectónica de las fases analizadas (C Proyecto Modular 2020). 


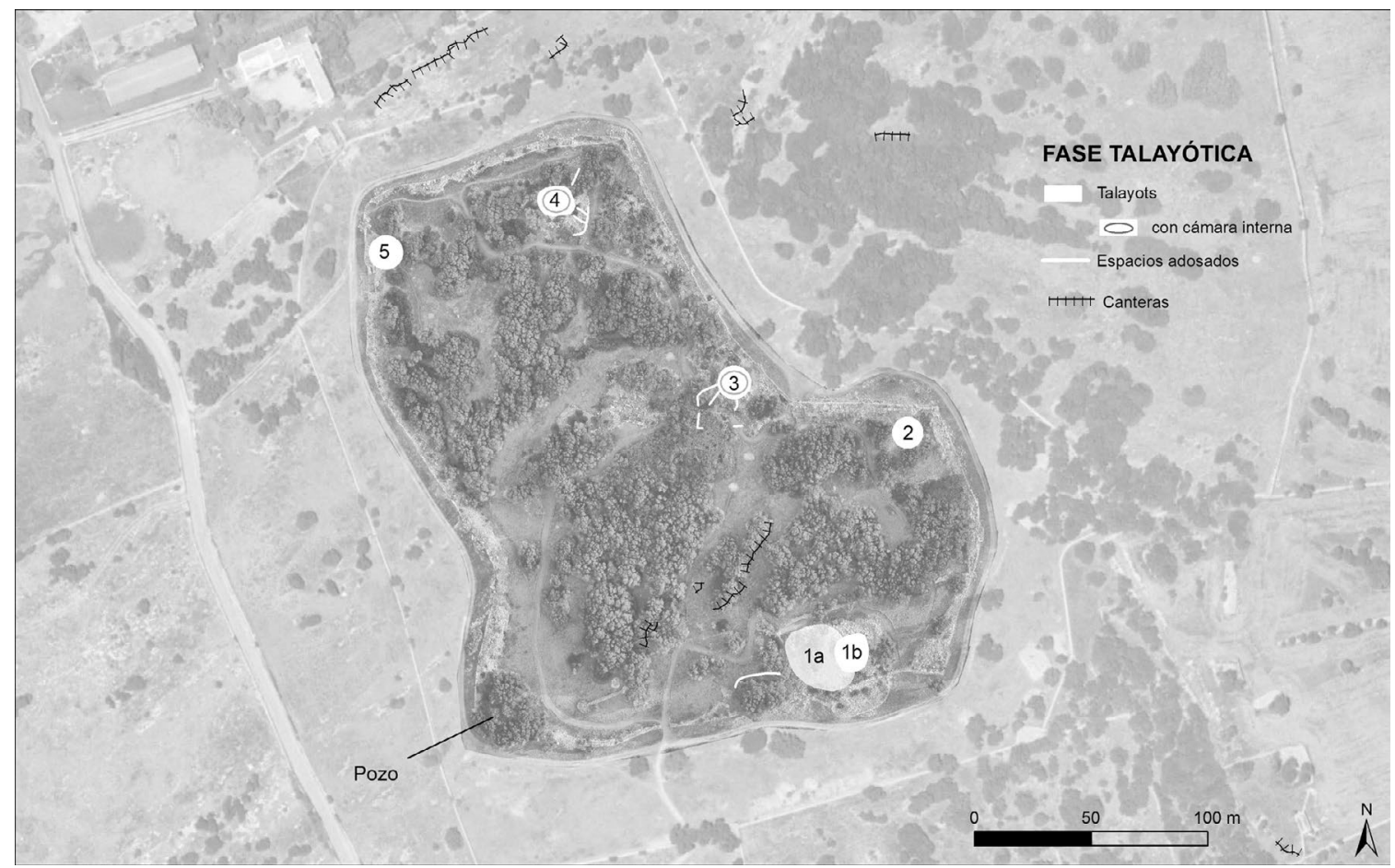

Figura 6. Estructuras documentadas de la fase talayótica (C) Proyecto Modular 2020)

nificado y funcionalidad, ampliamente debatidos, han de entenderse en la lógica del control territorial y la apropiación simbólica del espacio, pero seguramente también del almacenamiento y la redistribución de los excedentes, aspectos que fundamentarían el valor identitario y cohesionador de estos lugares para las comunidades que los construyeron (Lull et al., 2001; Ramis, 2017). En cuanto a la cronología, a pesar de las divergencias que se aprecian entre islas, hay datos recientes en Menorca que apuntan a la construcción de algunos de ellos hacia los siglos XI-X a. C. (Anglada et al., 2012), aunque la mayoría se encuadrarían entre inicios del primer milenio y los siglos VII-VI a. C.

En Son Catlar hemos identificado cinco talayots (Fig. 6), de los que al menos cuatro son hoy visibles. Numerados desde el sur y en sentido contrario a las agujas del reloj, el talayot número 1 es hoy el más destacado, sobredimensionado por la acumulación contemporánea de piedra a sus pies. Este talayot presenta una peculiaridad que nos permite plantear la existencia de dos fases: una estructura de planta trapezoidal y unos $13 \mathrm{~m}$ de diámetro (1b) parece superponerse a otra de mayor tamaño -unos $25 \mathrm{~m}$ de diámetro- (1a), que sería, por tanto, anterior. En consecuencia, y siempre teniendo en cuenta que hasta que dispongamos de dataciones exactas de cada uno de los monumentos nos movemos en el terreno de la especulación, este gran talayot 1a no solo sería el mayor del poblado, sino que pudo haber sido el primigenio. Sus enormes dimensiones, excepcionales en el contexto de las islas, nos parecen apuntar también en esa dirección. De esta forma, tendríamos una "fase 0" con un solo talayot al que habrían seguido los otros cinco -de dimensiones semejantes y organización espacial relativamente regular- que presumimos más o menos contemporáneos. El talayot número 2 está ubicado unos $80 \mathrm{~m}$ al norte, muy alterado por la construcción del encintado en la fase siguiente; el número 3 se ubica unos $60 \mathrm{~m}$ al oeste del anterior y consta de cámara y pilar central; y el 4 es el más septentrional, y dispondría también de una cámara en la parte superior, hoy colapsada. Finalmente, el talayot 5 se encuentra $60 \mathrm{~m}$ al oeste y hoy apenas quedan en pie tres hiladas intestadas en el lienzo de la muralla, por lo que pasa prácticamente desapercibido (Pericot, memoria inédita; Juan, 1993, p. 57).

Aparte de estos cinco talayots, tan solo podemos asociar con esta fase un conjunto de muros de factura similar en los talayots 3 y 4 , que conformarían espacios adosados a los turriformes que podríamos paralelizar quizá con el edificio adosado al talayot oeste de Cornia Nou, dedicado seguramente al almacenamiento y redistribución de alimentos (Anglada et al., 2012). Esto resulta de enorme importancia dado el desconocimiento que existe sobre las viviendas $u$ otras estructuras de la fase talayótica. 
Desde el punto de vista espacial, los talayots se despliegan a lo largo de la ligera elevación donde se emplaza el poblado, manteniendo una relativa equidistancia (unos $100 \mathrm{~m}$ ) que marca tres agrupaciones: los talayots 4 y 5 al norte, los talayots 2 y 3 en el centro y el talayot 1 al sur, que es el más cercano al pozo de la esquina SO. Partiendo de nuevo de la idea de que los talayots estuvieran integrados en un conjunto contemporáneo, esta disposición ciertamente racional y simétrica parece revelar la existencia de distintos grupos -familias extensas o clanes- asociados a cada talayot, de carácter aparentemente igualitario, que comparten y se reparten un mismo espacio en el que el pozo tendría un papel aglutinador como punto de referencia esencial para la vida. Visto de esta manera, los espacios vacíos en torno a los talayots, de dimensiones semejantes, podrían haber albergado viviendas de materiales perecederos, inapreciables en el registro arqueológico hasta el momento, y que no se "petrificaron" hasta la fase posterior.

Aunque la cerámica talayótica es prácticamente inexistente en superficie, las recientes excavaciones aportan algunas evidencias -incluso restos biológicos datados por $\mathrm{C} 14$ en los ss. X y IX a. C. (Prados et al., 2017b, muestras BETA475668, 1027-891 cal BC y BETA561040, 936-816 cal BC)-que demuestran un uso intensivo del lugar y por tanto que los talayots conformaron efectivamente un poblado. De hecho, sus cinco talayots y su extensión aproximada de 3 ha sitúan a Son Catlar a la cabeza de los poblados menorquines, seguido de otros como Torre d'en Galmés con tres talayots o, en el entorno más cercano, Torrevella d'en Lozano con cuatro y Montefí con tres. Dada además la prominencia visual de estas grandes atalayas, consideramos que la comunidad que habitaba en Son Catlar pudo haber controlado un amplio territorio -que rondaría los $30 \mathrm{~km}^{2}$-en el cuadrante SO de la isla, incluyendo quizá poblados de menor entidad como Santa Rosa d'Egipte o Torrellafuda, y limitando a $\mathrm{O}$ y S con el mar, al norte con el mencionado Montefí y al E con los barrancos de Santa Anna o Algendar (Juan, 1993, p. 37). Si bien es difícil determinar el grado de relación o dependencia de los poblados de menor entidad respecto a los mayores, así como la existencia de límites claramente definidos entre ellos, sí parece claro que en la fase talayótica existe una fuerte competencia entre grupos por un territorio cada vez más intensamente ocupado, que se refleja en el valor simbólico de los talayots como referentes de la comunidad, una voluntad de control visual y una cierta jerarquización entre asentamientos (Calvo, 2009, pp. 54-62).

Es importante recordar que los asentamientos talayóticos se ubican generalmente apartados de la costa, es decir, la explotación de los recursos del mar o los intercambios comerciales no solo no parecen una prioridad para estas poblaciones, sino más bien una fuente de inseguridad. Pese a ello, la comunidad asentada en Son Catlar, a tan solo $4 \mathrm{~km}$ de la costa, estaría en disposición de liderar los primeros contactos con los fenicios que empezaban a frecuentar estos mares y que, al menos desde el s. VIII a. C., estaban instalados en Ibiza (Ramon, 2007). Si bien el interés por Mallorca y Menorca sería entonces marginal (Castrillo, 2005; Quintana y Guerrero, 2005), los primeros ensayos de "intercam-

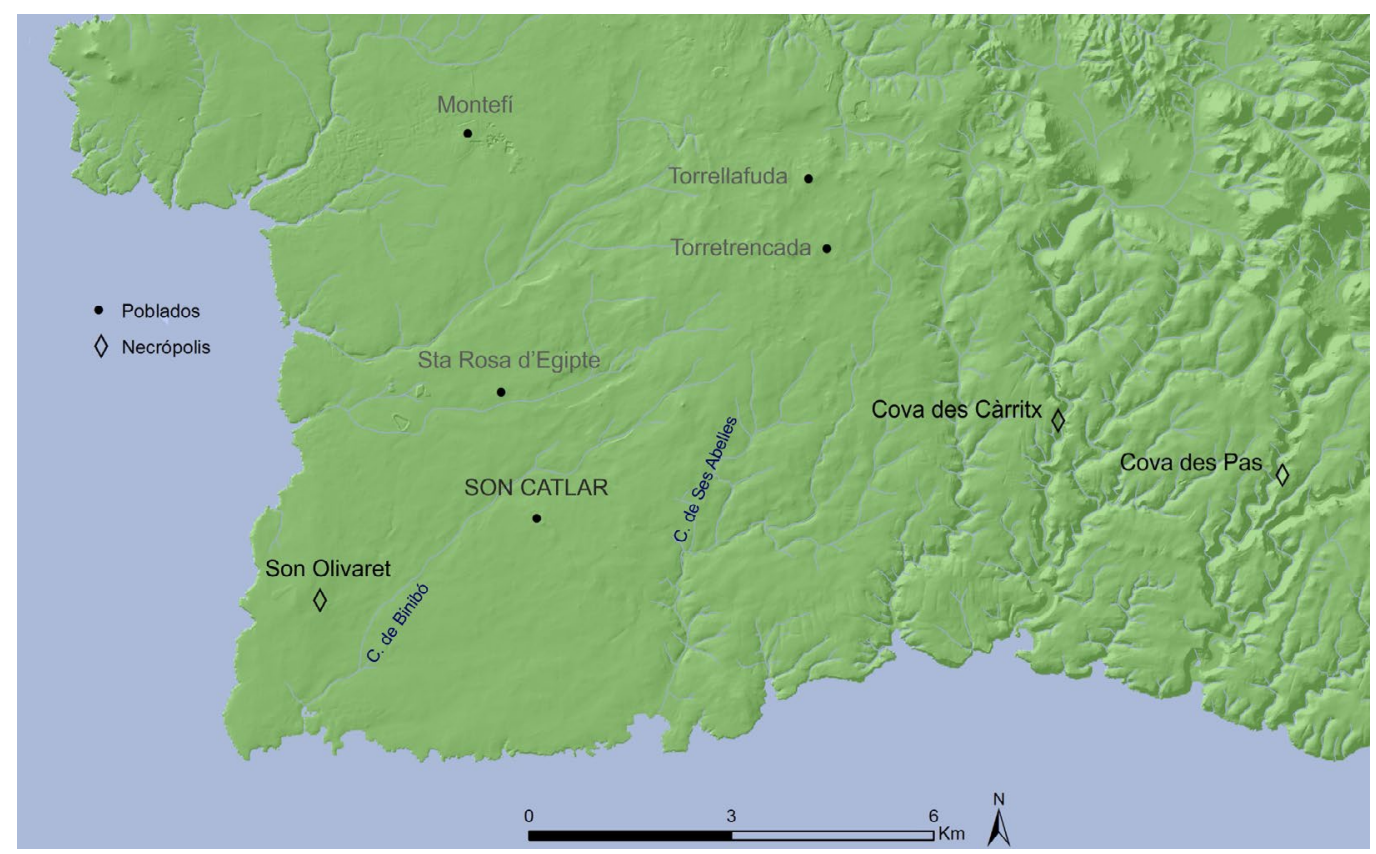

Figura 7. Fase talayótica. Yacimientos citados en el texto (C Proyecto Modular 2020). 


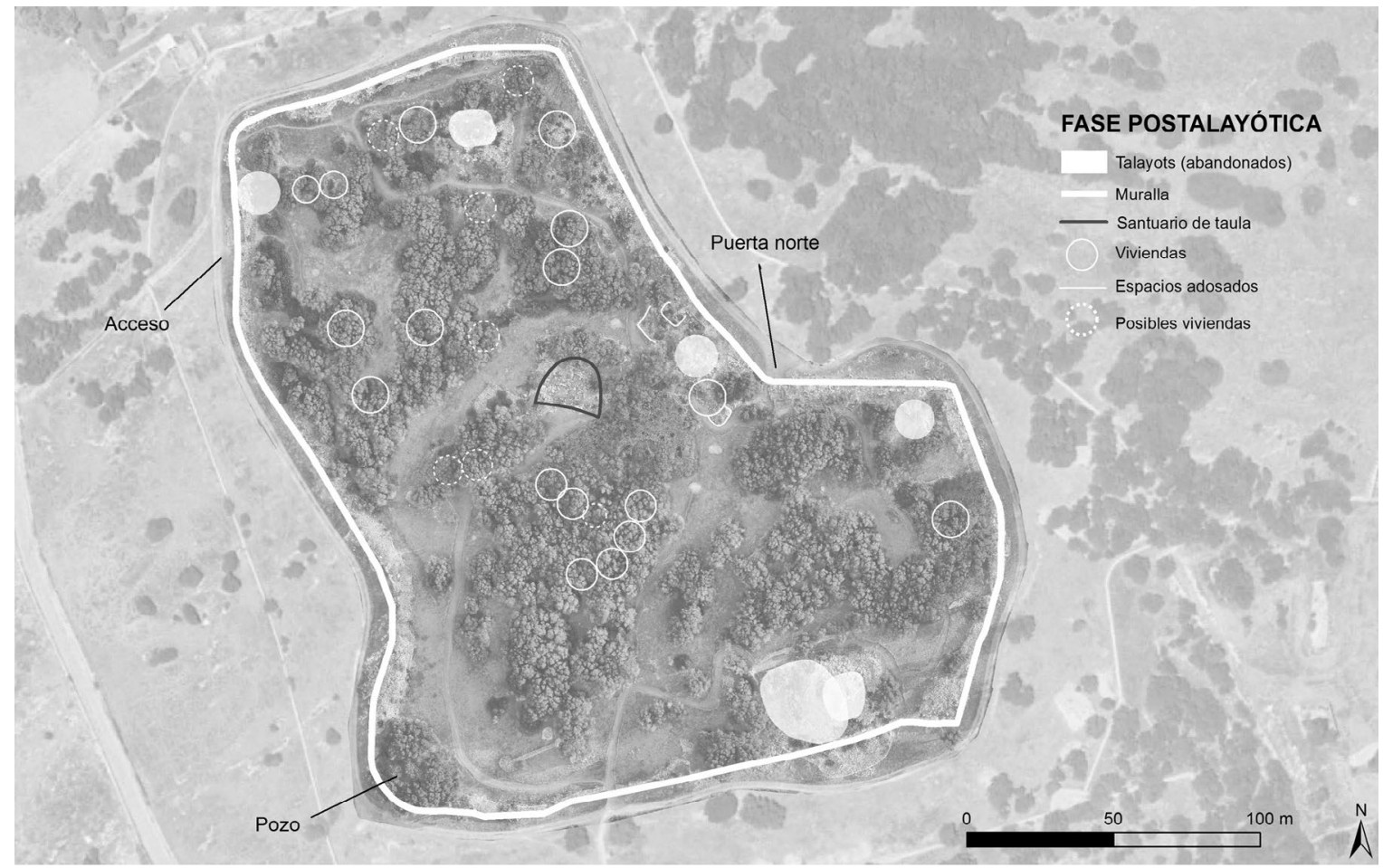

Figura 8. Estructuras documentadas de la fase postalayótica (C) Proyecto Modular 2020).

bio aristocrático" jugaron sin duda un papel destacado en la propia conformación de las culturas talayóticas (Guerrero, Calvo y Salvá, 2002). Aunque en Son Catlar no contamos aún con evidencias directas de estos contactos iniciales, es precisamente en este cuadrante de la isla donde se concentran las primeras importaciones de objetos suntuarios - de hierro, estaño o fayenza- en contextos funerarios como la Cova des Càrritx, la Cova des Pas o Son Olivaret (Guerrero, Calvo y Salvá, 2002; Simón et al., 2016; Llull et al., 2019). Si bien estas necrópolis estuvieron en uso desde la fase precedente, su frecuentación hasta inicios de la época talayótica y el papel destacado de Son Catlar en ese territorio nos permite señalar su importancia en este contexto de apertura al comercio mediterráneo. No ha de sorprendernos por tanto que, en la última de las necrópolis citadas, situada a tan solo $3,5 \mathrm{~km}$ de nuestro poblado, se haya identificado una población genéticamente diversa con influencia, incluso, de poblaciones próximo-orientales (Simón et al., 2016, pp. 345 y 346) (Fig. 7).

\subsection{Fase postalayótica (AProx. V-II a. C.): UN MOde- LO NUEVO DE POBLADO}

La fase que sin duda caracteriza Son Catlar es la conocida como postalayótica o talayótica final, correspondiente al Hierro II y definida por un nuevo modelo de poblado dotado de muralla, santuario de taula y grandes viviendas circulares.

Hacia los siglos VI-V a. C. se erige en Son Catlar una muralla de cerca de $1 \mathrm{~km}$ de perímetro que delimita una extensión de 4,4 ha e incluye los cinco talayots y el pozo de la fase precedente (Prados et al., inédito ${ }^{6}$ ). Este dato es esencial, implica una voluntad expresa de vincularse con dichos monumentos, símbolo de la fase anterior y por lo tanto de los ancestros, de materializar los límites de un espacio que pertenecía ya a esa comunidad. El hecho de que la muralla reutilice y aproveche materiales de los talayots demuestra que estaban en desuso, lo que no resta valor al hecho de incorporarlos - de forma solo simbólica si se quiere- en el nuevo poblado. La fortificación se erige con la técnica constructiva que caracteriza esta fase: un zócalo de bloques horizontales que soporta un alzado de ortostatos y mampostería (Hernández-Gasch y Aramburu-Zabala, 2005) (Tab. 1); siglos después de su erección, se ejecutó un plan de refortificación vinculado con la segunda guerra púnica (Prados y Jiménez, 2017).

6 Prados, F., León, M. J., Jiménez, H., Torres, O. y De Nicolás, J. C. (2019). Análisis arqueológico y documental de la arquitectura fenicio-púnica de Menorca. V fase. Informe anual 2019 de la intervención arqueológica en Son Catlar (Ciutadella de Menorca). Original inédito depositado en el Consell Insular de Menorca. 
El santuario de taula fue construido con una técnica idéntica a la de la muralla y presenta la composición habitual en estas edificaciones únicas de la Protohistoria de Menorca: una planta absidal y un elemento central en forma de $\mathrm{T}$-la taula- compuesto por un ortostato vertical coronado por otro horizontal; en Son Catlar, como muestran las fotos de Cartailhac, su desplome hubo de producirse antes de 1892. Aunque no disponemos de consenso en cuanto al origen de estos santuarios, debido a excavaciones antiguas y poco sistemáticas como en Son Catlar, sí de contextos de uso bien fechados entre los siglos V y III a. C. en poblados como Torralba (Fernández-Miranda, 2009), Torre d'en Galmés o So Na Caçana (Micó, 2005), cuyos materiales apuntan a una indudable influencia púnica en la ritualidad de las sociedades postalayóticas (De Nicolás, 2015). En el caso de Son Catlar, esto se ve acentuado por la existencia de una cisterna, que evidencia el papel del agua en el ritual, y el hallazgo de dos inscripciones en lengua púnica interpretadas como posibles evidencias de culto a Caelestis -interpretatio de Tanit-y Baal Hammon (Torres Bagur, Obrador y De Nicolás, 2017).

Junto a la muralla y el santuario de taula, el principal elemento de esta fase son los citados cercles, unidades domésticas características de este periodo y que, tanto por los materiales asociados como por dataciones radiocarbónicas, sabemos que fueron construidos a partir del siglo VI a. C. y ocupados en muchas ocasiones hasta época altoimperial (Serra, 1965; De Nicolás, 1997; Gornés et al., 2001; Pons, 2016). Estas estructuras se caracterizan por sus plantas circulares o de herradura, sus paramentos de ortostatos y sus grandes dimensiones -entre 80 y $120 \mathrm{~m}^{2}$-, así como por la fragmentación de su espacio interior en torno a un patio a cielo abierto. Dicha disposición, así como el empleo de muros de pilares o de cal y tierra en morteros y pavimentos, apunta a la incorporación de formas y técnicas de tradición púnica en la arquitectura doméstica postalayótica (Torres Gomariz, 2016). Debido a su carácter repetitivo y estandarizado, la identificación de alguna de sus partes (muros curvos, pilastras, umbrales, elementos muebles como los amolons $^{7}$-molinos-y las pilas o morteros) nos ha permitido localizar 17 viviendas y 7 casos por confirmar en el poblado (Fig. 8). Como ya señalaba Serra (1965), las casas se encuentran generalmente adosadas unas a otras, formando grupos de incluso cinco ejemplares; llama la atención la presencia ocasional de un muro perimetral que conforma un espacio común, privativo respecto al exterior, que tendría paralelos en Torre d'en Galmés (Sintes e Isbert, 2009; Carbonell et al., 2015). Otro rasgo fundamental es la presencia recurrente de estructuras anejas cubiertas por grandes lajas sustentadas por pilares y conocidas generalmente como "salas hipóstilas" (Flaquer, 1952). Aunque de nuevo carecemos de información arqueológica rigurosa que

7 Indicamos el término en catalán dada su preeminencia en la historiografía balear. Diccionari català-valencià-balear de A. M. Alcover i F. de B. Moll: Amoló m. Edición electrónica: https:// dcvb.iec.cat/ (consultado 15/03/2020).

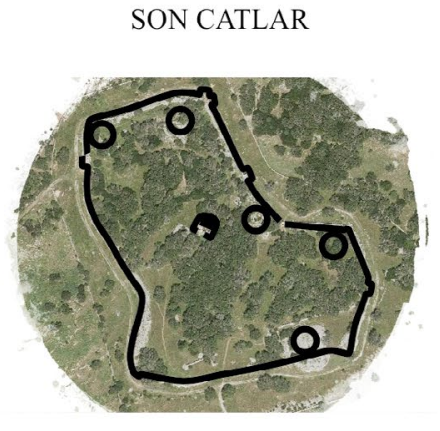

4,4 ha
TORRE D'EN GALMÉS

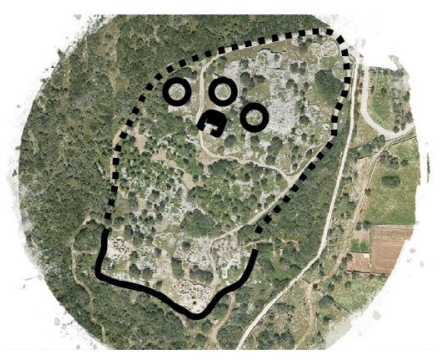

4,2 ha
TREPUCÓ

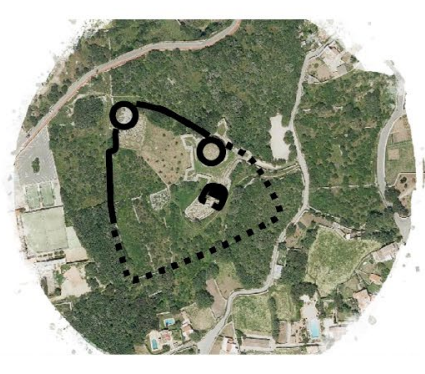

1,8 ha

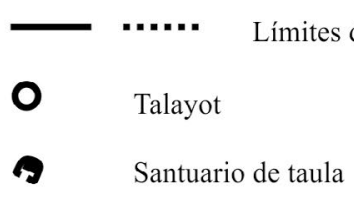

Límites del poblado 


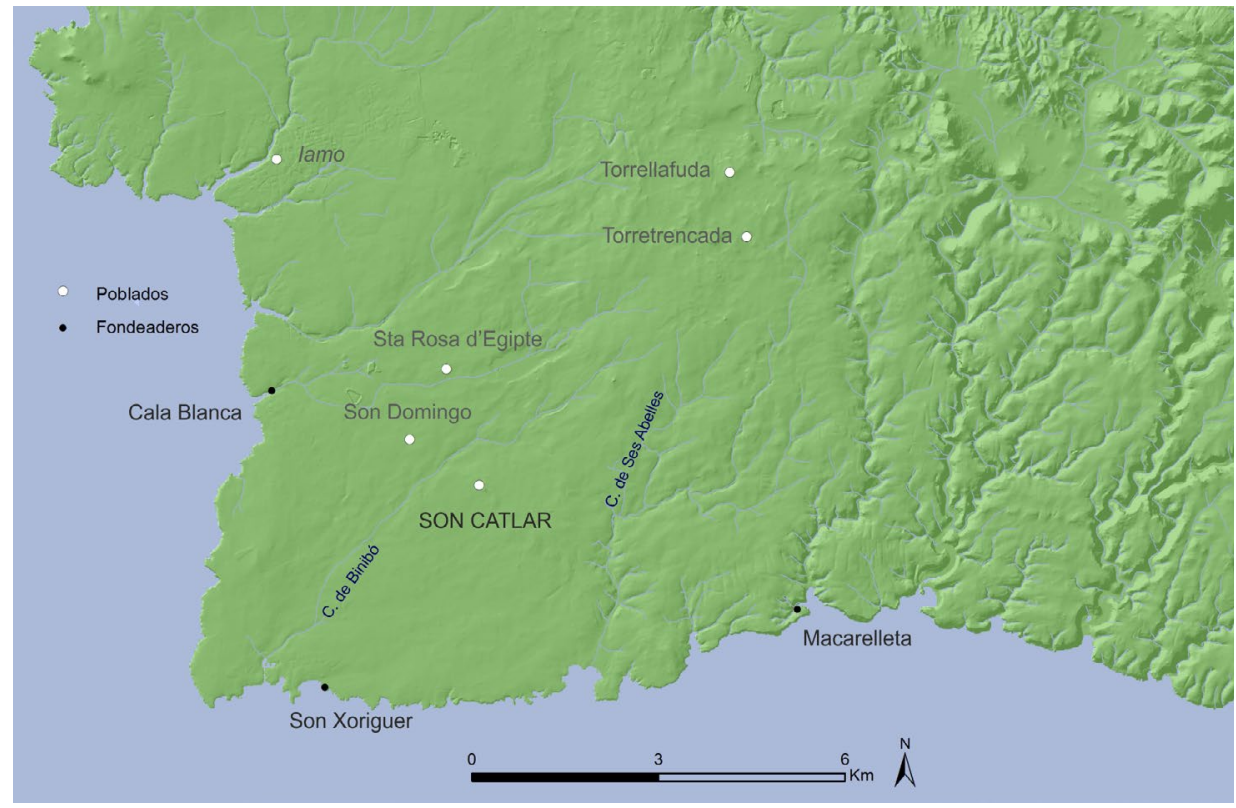

Figura 10. Fase postalayótica. Yacimientos citados en el texto (@ Proyecto Modular 2020).

nos ilustre sobre su funcionalidad, su forma y materiales asociados han llevado a considerarlos espacios de almacenaje o estabulación (Plantalamor, 1991). En Son Catlar existe al menos una de estas estructuras, en la parte posterior del talayot 3 (Pericot, memoria inédita).

El carácter homogéneo y repetitivo de las viviendas y la llamativa continuidad de las mismas a lo largo del todo el periodo -fenómeno constatado en la mayoría de poblados de la isla-, denota la importancia de la casa en la sociedad postalayótica, que nos lleva a ver ciertas semejanzas con las llamadas "sociedades de casa” (González-Ruibal y Ruiz-Gálvez, 2016). En paralelo, hay algunos rasgos que nos parecen apuntar a una competencia entre grupos (o casas) por el espacio del poblado y a una incipiente jerarquización social ${ }^{8}$ : la conformación de conjuntos de viviendas de diferentes dimensiones y de espacios privativos dedicados a la producción, la ubicación en relación con el santuario o la excesiva concentración de molinos en algunos de estos conjuntos -hasta 38 en el cercle 7 de Torre d'en Galmés (Carbonell, 2012, p. 102)-, que apuntaría a un acceso diferenciado a los medios de producción y por tanto a una competencia, también, por las tierras cultivables. Sería interesante explorar otros aspectos en que pudiera manifestarse esa desigualdad crecien-

8 Tema de la tesis doctoral "La sociedad postalayótica bajo órbita púnica. Viviendas y grupos domésticos en el archipiélago balear (VI-II a. C.)" de O. Torres Gomariz, Universitat d'Alacant, 2021. te, como el consumo de vino o el mundo funerario. En Son Catlar, como en el resto de la isla, el material más común en superficie son las ánforas vinarias púnico-ebusitanas de los siglos III-I a. C. (Orfila y Sintes, 1984; Juan, Pons y Juan, 1998; Pons, 2012; Jiménez Vialás et al., 2021) pero será necesario valorar en qué proporciones aparecen en cada una de las viviendas; respecto a las necrópolis de este periodo, sí parece haber una creciente diferenciación social, reflejada en la monumentalidad de los hipogeos y la composición de los ajuares (Gornés, 1996, p. 101; Carbonell, 2017; Sintes y León, 2019, pp. 41-45).

En cuanto a la organización espacial de esta fase, y aunque la parcialidad de la información desaconseja por el momento la aplicación de herramientas analíticas complejas empleadas en otros contextos (Ayán, 2003), hay un aspecto que destaca sobre los demás: el papel del santuario como elemento central, situado además a medio camino de los dos únicos accesos conocidos para esta fase (la puerta norte en el flanco oriental y el acceso occidental). Son Catlar refleja por tanto el carácter cardinal de estos santuarios en los poblados postalayóticos, recalcando dos particularidades respecto a los talayots de la fase precedente: la existencia de un solo santuario por poblado y su indudable naturaleza cultual, que denotan la importancia del ritual como elemento cohesionador de las sociedades postalayóticas y la existencia de un poder político centralizado, de marcado carácter religioso.

La entidad que alcanza el poblado en este periodo se refleja en sus dimensiones: 4,4 ha frente a las 4,2 ha 


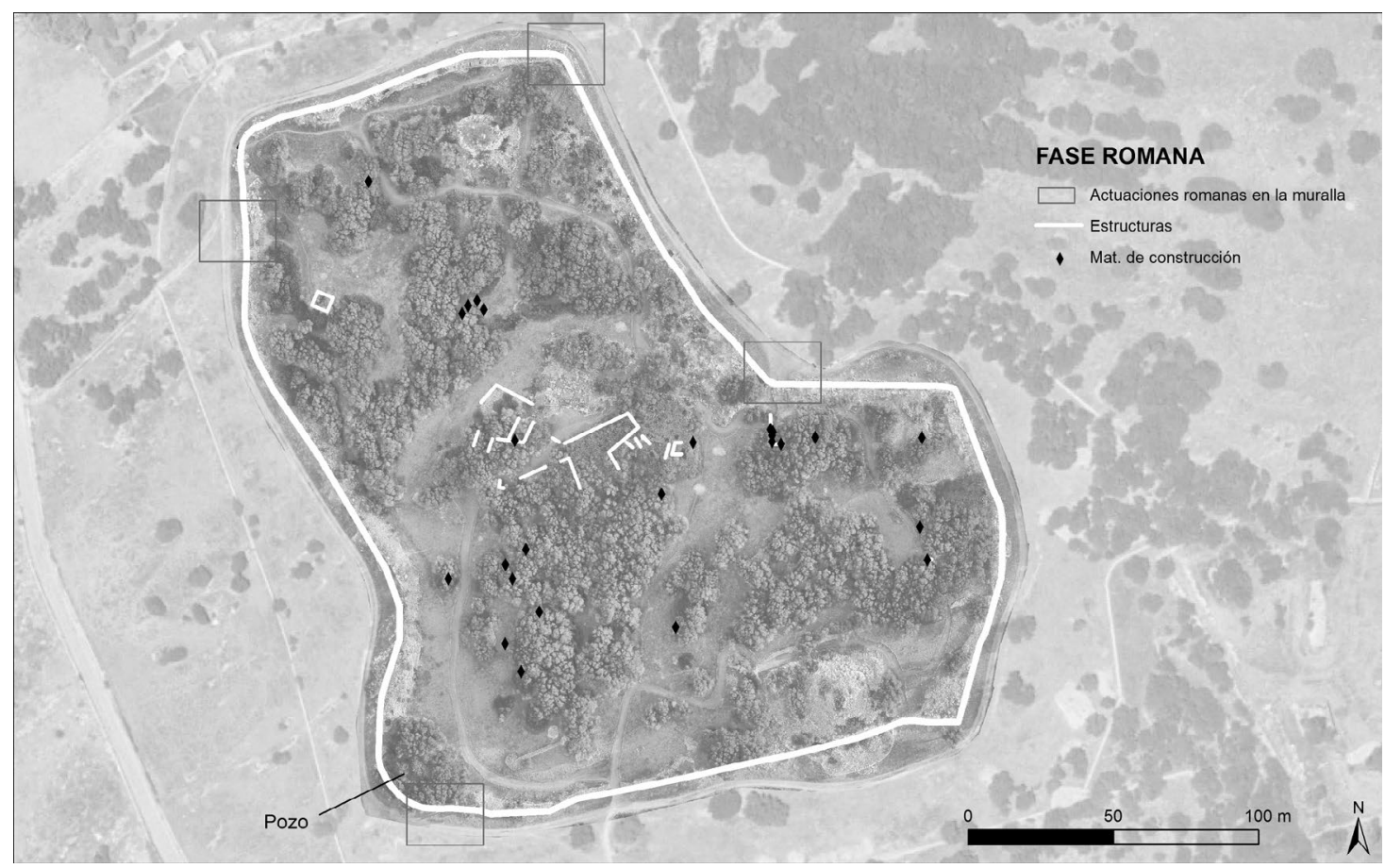

Figura 11. Estructuras documentadas de la fase romana (C) Proyecto Modular 2020).

de Torre d'en Galmés o las 1,8 ha de Trepucó sitúan de nuevo a Son Catlar a la cabeza de los poblados menorquines (Fig. 9). En función de las viviendas identificadas, y considerando una media de 6 personas por casa, tendríamos un mínimo teórico de 102 habitantes, lo que casi duplica los 66,8 por poblado propuestos para este periodo por De Cet (2017, pp. 144-145), algo que parece coherente con la excepcionalidad de Son Catlar en el contexto de la isla. A escala territorial hay una acentuación de la jerarquización respecto a la fase precedente. El poblado concentra mayor población y se reduce el número de núcleos que, en función de su inferior tamaño, consideramos subsidiarios, y que parecen experimentar una cierta diversificación: poblados como Santa Rosa d'Egipte y Torrellafuda, o el posible santuario de Son Domingo (De Nicolás y Obrador, 2015). La conexión con el mar podría pivotar sobre los embarcaderos de Cala Blanca o los asentamientos costeros de Son Xoriguer y Macarelleta (Juan, 1993, p. 37; Martín et al., 2020), si bien en este periodo, sobre todo en su fase final, sería seguramente Iamo -actual Ciutadella- el principal puerto de esta parte de la isla debido a sus inmejorables condiciones para el fondeo (Navarro, 2004; Aguelo et al., 2011) (Fig. 10); el hecho de que las fuentes presuman un origen púnico para Mago y Iamo (Estrabón, Geo., III, 5, 1 o Severus Minoricense, Epist., 2, 5), parece apuntar a la existencia de enclaves portuarios dinámicos con anterioridad a Roma (Sánchez León, 2003; Orfila y Riera, 2004).

A la luz de los datos expuestos, podemos decir que la fase postalayótica de Son Catlar es perfectamente representativa del periodo, ya que los poblados de cercles - no siempre dotados de santuario de taula o muralla-son el patrón característico del momento. La singularidad de sus elementos constituyentes, y sobre todo la generalización del modelo en la isla, evidencian la existencia de unas comunidades muy semejantes en su composición y estructura, donde determinados grupos podría estar ejerciendo su dominio sobre el resto, al amparo de la religión y en virtud del control de los excedentes y el intercambio, un fenómeno observado también en la vecina Mallorca (Calvo, 2009, p. 66). Este fenómeno está sin duda ligado a la creciente apertura de las sociedades insulares al ámbito mediterráneo a través del mercenariado y sobre todo del intenso comercio con los púnicos de Ibiza. Sin negar en modo alguno el papel activo de las comunidades baleáricas en un proceso histórico que sin duda protagonizan (Calvo y García, 2019), nos parece que las relaciones con los púnicos trascendieron el mero comercio. La posible existencia de un "monopolio ebusitano" en Menorca, que controlaría la navegación, el comercio y las levas (Ramon, 2017), explicaría la marcada influencia de la cultura púnica en diferentes ámbitos, desde los poblados, la arquitectura o la dieta (Prados, Jiménez y García, 2017) hasta el que es sin 


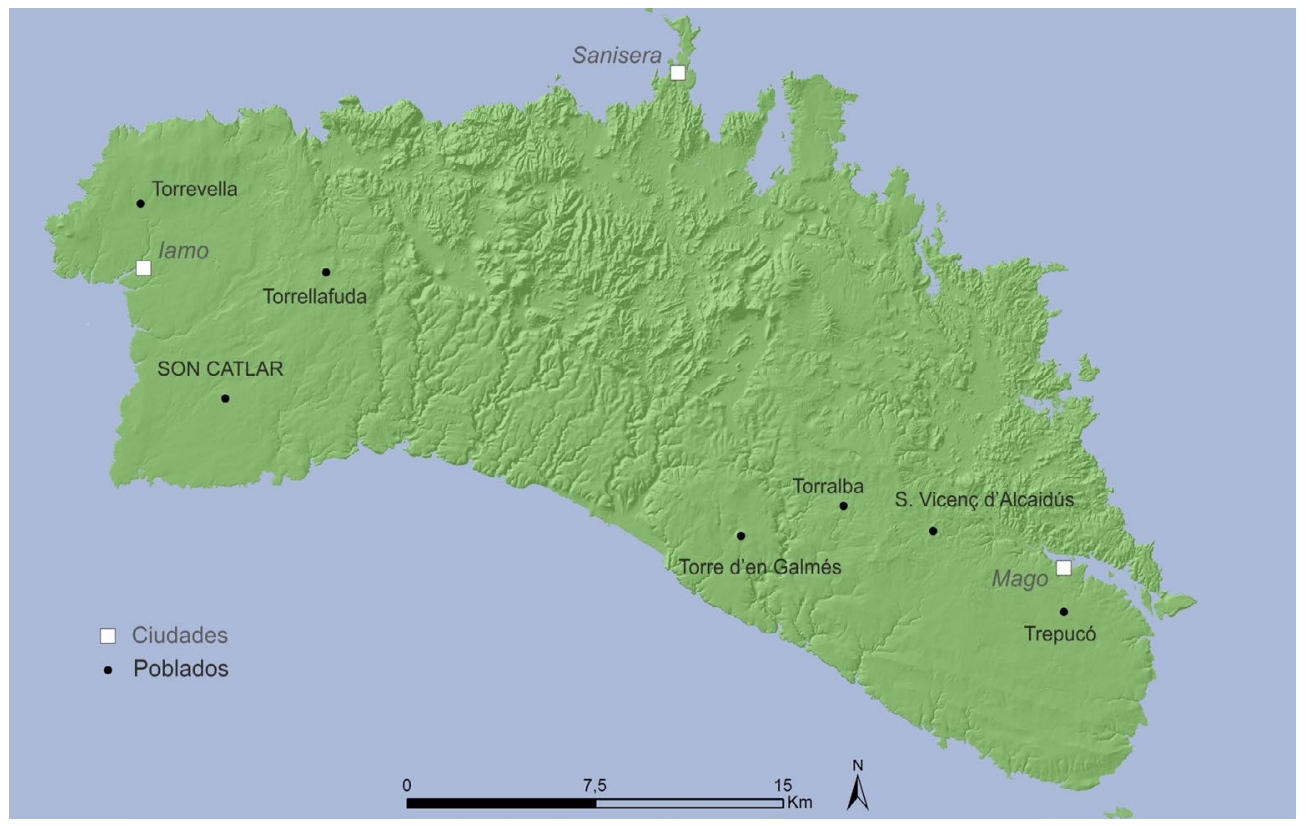

Figura 12. Fase romana. Yacimientos citados en el texto (C Proyecto Modular 2020).

duda el dato más revelador: la existencia de prácticas religiosas púnicas formando parte de la rica religiosidad postalayótica (Sánchez López et al., 2016; De Nicolás, Gornés y Gual, 2017). Todo ello le confiere a la cultura postalayótica menorquina un carácter marcadamente singular, diferente respecto a la fase precedente, aunque enraizada en ella, y respecto a Mallorca.

\subsection{FASE ROMANA ¿UNA LACESE INDÍGENA ROMANIZADA? (II A. C.-VI D. C.)}

La fase romana es una de las que más interrogantes plantea y a la vez mayor potencial ofrece, teniendo en cuenta que es una faceta exiguamente conocida en Son Catlar. Conviene primero mencionar que en el contexto de las Baleares ${ }^{9}$ la ocupación de poblados de origen talayótico en época romana parece una pauta común tanto en Mallorca como en Menorca (Fernández-Miranda, 1976; De Nicolás, 1983 y 2003; Orfila y Sintes, 1984; Guerrero, 1990). La dificultad, como bien ilustra el caso de Son Catlar, reside en valorar la naturaleza de esa ocupación y su evolución en el tiempo.

Existían desde hace tiempo indicios de frecuentación del lugar en época romana, desde hallazgos

9 La investigación sobre la romanización de las Baleares se ha centrado especialmente en la Insula maior; algunos de los trabajos principales sobre el tema son Arribas, Tarradell y Woods, 1973; Tarradell, 1983; Orfila, 1988; Guerrero, 1990; Zucca, 1998; García Riaza y Sánchez León, 2000; Orfila y Riera, 2004. puntuales como cerámica, metales e incluso una basa de columna emplazada hoy en la casa predial adyacente (Óleo y Quadrado, 1874; Flaquer, 1922, p. 111; De Nicolás, 1983; Orfila y Sintes, 1984), hasta niveles de esta cronología en la zona de la puerta norte (Juan, Pons y Juan, 1998). Pero sin duda el hallazgo más destacado son dos inscripciones con las leyendas LACESE (CIB 166) y LACESEN (CIB 167) (Veny, $1965)$, interpretadas por M. Mayer como mojones delimitadores del territorio de Iamo y una comunidad de origen indígena denominada Lacese ${ }^{10}$, en un momento inicial de la romanización (2005, pp. 44-45).

En los últimos años, las intervenciones arqueológicas del Proyecto Modular han sacado a la luz lo que parece ser el reflejo material de la conquista romana en el poblado: el desmantelamiento sistemático y posterior remodelación de parte de las estructuras defensivas, asociado a la llegada de materiales itálicos que forman potentes basureros extramuros fechados en la primera mitad del s. I a. C. (Prados et al., 2017b y 2019). Era necesario por tanto comprobar la existencia de edificaciones romanas también en el interior del poblado.

En las prospecciones hemos identificado una serie de estructuras cuadrangulares realizadas en un aparejo de hiladas regulares -un vittatum rudimen-

10 Recientemente se ha propuesto, valorando la relación de una de las piezas con el santuario, que pudiera tratarse de un teónimo (Torres Bagur, Obrador y De Nicolás, 2017). 
tario o pseudo vittatum (Tab. 1)-. No descartamos que alguna de ellas pudiera tener relación con las citadas actuaciones en la muralla, pero la presencia de material constructivo romano, que no se generaliza en la isla hasta después de la Era, nos lleva a atribuirlas a época imperial. Podemos individualizar hasta seis estructuras correspondientes seguramente a un mismo conjunto, dada su homogeneidad constructiva. Salvo una posible cisterna en el entorno del talayot 5 , todas se localizan en la zona central, en torno al santuario y por tanto en un lugar neurálgico espacial y simbólicamente. Los restos de materiales de construcción dispersos (opus signinum, opus caementicium y tegulae) se concentran en la mitad sur, más sometida al desmantelamiento de sus estructuras y por tanto al desplazamiento de los materiales, pero parecen conservarse in situ en áreas como la puerta norte (Fig. 11).

Por lo tanto, parecen distinguirse dos momentos bien diferenciados dentro de la fase romana: uno primero encuadrable de forma genérica entre el final de la segunda guerra púnica y el cambio de era, marcado por un aparente mantenimiento de la vida del poblado, cambios de calado en la fortificación y la llegada masiva de materiales itálicos; y un segundo en que se construyen un conjunto de edificios de tipología romana, ya en un momento avanzado, hacia los siglos I y II. Este esquema se compadece con lo planteado para la romanización de las Baleares, inaugurada con la conquista militar de Metelo en el 123 a. C., pero de la que el registro arqueológico no muestra reflejo claro anterior al segundo cuarto del s. I a. C. (Guerrero, 1990, pp. 226-227; Orfila, Arribas y Cau, 1999; Orfila, Chávez y Cau, 2006, p. 135; Cau y Chávez, 2003, p. 32). La mayoría de investigadores explican hoy ese hiato entre la fecha oficial de la conquista y los restos de presencia romana incontestable por la naturaleza militar del primer impacto romano. De tal modo, se ha planteado el origen campamental de Palma y Pollentia, que no se convertirían en verdaderas colonias hasta el fin de las guerras sertorianas (Mattingly, 1983, pp. 245-246; Orfila, Arribas y Cau, 1999, p. 101; Cau y Chávez, 2003, p. 32). En Menorca, de las tres civitates que menciona Plinio ( $\mathrm{NH}, 3,78)$, Iamo, Mago y Sanisera, está confirmado el origen campamental de esta última, y las dos restantes son referidas por Mela (Chor. II, 124) como castella, lo que subrayaría su naturaleza defensiva (De Nicolás, 1983, p. 265; Orfila, Chávez y Cau, 2006, p. 143) (Fig. 12).

En Son Catlar, las estructuras y materiales del primer momento mencionado nos llevan igualmente a subrayar un carácter defensivo en el contexto de la conquista y la inseguridad causada por las activi- dades piráticas -tanto sufridas como protagonizadas por los baleáricos- a las que aluden las fuentes (Orfila, 2008, pp. 23-25; Puig Palerm, 2014). Es difícil valorar, sin embargo, la vida del poblado en este momento, más allá de presumir la continuidad del uso de las viviendas o del santuario, como sabemos para otros enclaves (De Nicolás, 2003; Orfila et al., 2017), dada la escasa visibilidad de posibles refacciones o nuevas construcciones. Sin embargo, los mencionados termini resultan fundamentales en este punto, pues revelarían la existencia de una comunidad indígena incorporada al sistema territorial romano, una estrategia habitual en la política de expansión de estos siglos (Mayer, 2005, pp. 44-45; García Riaza, 2006, p. 182).

En cuanto a la segunda fase, es evidente que las estructuras corresponden a un momento de consolidación de los modelos romanos, con materiales y tipos constructivos que no se generalizan hasta entrada la época imperial. Avanzado el s. I y seguramente relacionado con la promoción jurídica de época flavia, Iamo y Mago experimentaron un auge urbano que parece haber ido en detrimento de algunos establecimientos indígenas, que se abandonan (De Nicolás, 1983, pp. 259-266; Orfila, 2008, p. 34). Son Catlar no parece haber sufrido ese final -o al menos volvió pronto a ser ocupado-, pero sí alteró de forma sustancial sus dimensiones y naturaleza: las estructuras del periodo anterior se abandonaron -sin que sepamos cuándo exactamente- y la llegada de nuevos materiales y una nueva arquitectura denotan cambios trascedentes. El conjunto de estructuras que asociamos con esta fase conforma una ocupación nuclear de 0,6 ha, que ascienden a 2 ha si incluimos otras evidencias como la cisterna o los restos de materiales de construcción, que conforman un "halo" en torno al conjunto de edificios. Se trata en todo caso de unas dimensiones nada desdeñables que van en la línea de lo que se ha propuesto, por ejemplo, para los vici de la isla de Djerba (Túnez) en función del material de superficie (Fentress, 2009, p. 157).

Nos encontramos pues ante lo que parece un núcleo rural ${ }^{11}$ plenamente romano. Vemos difícil considerarlo una villa dada la práctica ausencia de elementos de ostentación de una posible pars urbana o de evidencias de una producción claramente orientada a la exportación. De hecho, el campo menor-

11 Dada la dificultad de conciliar términos como villa o vicus con la realidad arqueológica (Fernández Ochoa, Salido y Zarzalejos, 2014, p. 114), nos limitamos a comentar sus características en el contexto del campo romano menorquín. 
quín de época romana se caracteriza precisamente por la ausencia de este tipo de explotaciones, lo que se achaca a la tan predicada pobreza del suelo (Juan, 1993, p. 52; De Nicolás, 2003, p. 124), la ausencia de vinicultura y oleicultura (Diodoro, $B H, \mathrm{~V}, \mathrm{XVII}$ ), $\mathrm{y}$ otros rasgos arcaizantes como la preponderancia del ganado ovino frente al bovino (Valenzuela, Alcover y Cau, 2017). En contraposición, hay una absoluta continuidad de los poblados postalayóticos, donde pasado el tiempo se erigen estructuras modestas de tipo rural, siempre asociadas a pozos, aljibes o cisternas que aseguren el suministro de agua (De Nicolás, 1983 y 2003; Orfila y Sintes, 1984); el mapa se completaría con necrópolis rurales (De Nicolás, 1983, pp. 267268; Orfila y Sintes, 1984, p. 24) así como pequeñas instalaciones costeras relacionadas con la pesca y el intercambio (De Nicolás, 2003, p. 121).

Son Catlar es un magnífico ejemplo de ese patrón, aunque quedan numerosos interrogantes abiertos, como si el poblado mantuvo su ocupación en todo momento o si se produjo un hiato entre las dos fases, y cuáles fueron las circunstancias o las implicaciones jurídicas de dicho cambio: ¿fue Lacese una civitas estipendiaria o un vicus dependiente de Iamo? ¿varió su condición entre ambas fases?

\subsection{FASE MEDIEVAL ISLÁMICA Y MODERNO- CONTEMPORÁNEA}

Poco sabemos por el momento de la evolución del poblado en los últimos siglos del periodo romano, lo que sugiere un posible abandono o un retraimiento significativo. En cuanto a época medieval, a pesar de que no hemos podido identificar estructuras ni materiales en nuestras prospecciones, sí hubo algún tipo de ocupación, a tenor de los materiales andalusíes recuperados tanto en las intervenciones en la puerta norte (Juan, Pons y Juan, 1998) como en otros lugares del yacimiento (Orfila y Sintes, 1984); información muy escasa que permite hablar de una fase medieval, pero no establecer su extensión ni naturaleza. Se trata en todo caso de un dato que no desentona en la isla, donde otros poblados como Torrevella d'en Lozano, Torrellafuda, Torralba, Torre d'en Galmés o Trepucó, por citar algunos de los principales, se mantuvieron ocupados tanto en época romana como islámica, hasta que la conquista cristiana en el s. XIII cambió de forma sustancial los modelos de hábitat (De Nicolás, 1983; Orfila y Sintes, 1984; Pérez-Juez, 2012).

Por otra parte, de las vicisitudes moderno-contemporáneas por las que atravesó Son Catlar dan buena cuenta las diferentes estructuras -muros, clapers o simples acumulaciones de piedra- que evidencian el uso del lugar como sementera hasta hace pocas dé- cadas y que constituyen un claro exponente del rico patrimonio menorquín de arquitectura en piedra seca (Jiménez Vialás et al., 2019, p. 159).

\section{VIVIR A LA SOMBRA DE LOS TALAYOTS: PAISAJE Y SOCIEDAD EN MENORCA}

Una vez expuestos los resultados de nuestras prospecciones, así como las líneas interpretativas que quedan abiertas, consideramos que este trabajo supone un salto cualitativo en el conocimiento de Son Catlar, a la vez que inaugura una línea de investigación que esperamos continuar. Creemos que su valor principal es doble: hemos ofrecido una primera aproximación a los conjuntos estructurales hoy visibles en superficie, estableciendo su adscripción cronológica y cultural para una mejor comprensión de las diferentes ocupaciones del poblado a lo largo de sus más de 1000 años de historia; consideramos además que la metodología planteada ha sido un éxito en cuanto al tiempo y los recursos invertidos, generando un amplio volumen de información de forma ágil, para su posterior interpretación. Esto demuestra que las técnicas no invasivas son un medio óptimo para aproximarnos al estudio del denso patrimonio menorquín, en especial de cara a la citada candidatura a la Lista de la UNESCO.

Gracias a la perspectiva diacrónica que nos brinda un estudio como este, podemos hoy considerar a Son Catlar un magnífico representante de procesos históricos de larga duración que afectaron a la isla de Menorca, como la conformación de las culturas talayótica y postalayótica, aunque también de acontecimientos reducidos en el tiempo, pero de profundo calado, como la segunda guerra púnica o la conquista romana.

Es indudable que la naturaleza insular, que impone fronteras claras y limitaciones medioambientales, ha desempeñado un papel fundamental en el desarrollo de estas comunidades, por lo que este poblado es también un inmejorable laboratorio para abordar las respuestas humanas a desafíos como la pobreza de suelos, las escasas precipitaciones o la ausencia de recursos atractivos (metales), que en el caso de Menorca explican su tardía ocupación respecto al resto de islas mediterráneas (Cherry y Leppard, 2018). El carácter insular marca además el ritmo de los tiempos históricos, con fases de aislamiento y apertura que ralentizan o aceleran los cambios experimentados por las sociedades isleñas (Febvre, 1970, p. 241). Si bien con el primer milenio a. C. se abrió en todo el Mediterráneo una fase definida por la "conectividad" que dio lugar a la expansión de fenómenos de importancia trascendental como la vida urbana (Horden y Purcell, 2000, p. 123), también a formas culturales particulares y únicas en las islas (Knapp, 2007; Kouremenos, 2017). Como 
hemos visto en este trabajo, Menorca participa de esos grandes fenómenos, si bien con un ritmo y unas particularidades propias: ausencia de grandes núcleos urbanos, conservadurismo en su economía y en su arquitectura, diferenciación social incipiente, ausencia de grandes monocultivos, incorporación del torno, la escritura o la planta cuadrada en plena época romana, y sobre todo, como bien ejemplifica Son Catlar, perduración de los lugares de hábitat. Una perduración que no implica una inmutabilidad en los sistemas de poblamiento, pues la presencia del hombre en el paisaje se va materializando a través de nuevos tipos de arquitectura, nuevas relaciones entre poblados y la atribución de nuevos significados a los hitos monumentales de momentos anteriores (Criado, 1993; Tilley, 1994).

Los talayots, concebidos como emblemas pétreos del vínculo de la comunidad con su territorio, adquieren nuevos significados con el tiempo, relacionados con el arraigo y los ancestros en época postalayótica, y con el refugio y la existencia de recursos ya en épocas romana o medieval; en los poblados postalayóticos son las murallas, los santuarios y las imponentes viviendas los que revelan la emergencia de los grupos familiares en el seno de las comunidades; finalmente, en las épocas romana e islámica, encontramos modestos enclaves rurales camuflados entre las ruinas de épocas anteriores, pero formando parte de territorios administrados por la ciudad.

En Menorca parece haber existido un cierto equilibrio entre recursos y población desde época postalayótica y hasta el s. XIX, a través de un poblamiento rural denso con escasos núcleos urbanos de tamaño reducido (De Cet et al., 2014). Estrategias como la preferencia por la plataforma miocena de la mitad sur de la isla, el control de los recursos hídricos, la agricultura de secano, la economía agropecuaria con predominio de ovicápridos y un tipo de hábitat concentrado, habrían asegurado la capacidad del medio para regenerar los recursos, la llamada "capacidad de carga" que en la isla se situaría en torno a los 30.000 habitantes (Fernández-Miranda, 1991, pp. 49-50; De Cet, 2017, pp. 193-195).

Por tanto, los enclaves donde las comunidades talayóticas erigieron sus singulares construcciones reunían unas condiciones idóneas para el hábitat -acceso al agua fundamentalmente- que las sociedades de épocas posteriores consideraron óptimas, pues de lo contrario habrían escogido otros lugares. Dada además la envergadura y omnipresencia de los talayots en el paisaje menorquín, han sido una referencia ${ }^{12}$ para la estructu-

12 Un caso similar y bien conocido son las nuragas sardas, que han ido adquiriendo nuevos significados a lo largo de los siglos (Blake, 1998). ración de los territorios de cada época, algo así como receptáculos de memoria social e hitos señalizadores de lugares potenciales para el hábitat, de ahí su relación estrecha-casi sistemática- con el poblamiento de épocas posteriores y, de forma muy señalada, con los llocs o fincas de épocas recientes, lo que demuestra el carácter resiliente del paisaje menorquín.

\section{AGRADECIMIENTOS}

Los autores del texto agradecen a los compañeros del Proyecto Modular por su colaboración en los trabajos en Son Catlar. A Gustau Juan le debemos diversas informaciones relativas al poblado y al Equip Cornia Nou el facilitarnos documentación gráfica. El manuscrito se ha beneficiado asimismo de los comentarios de Ignasi Grau (Universidad de Alicante) y los evaluadores anónimos, que han contribuido a mejorar el texto inicial.

\section{FUENTES CLÁSICAS}

Diodore de Sicile (1846). Bibliothèque historique. Traduction nouvelle avec une préface, des notes et un index par M. Ferd. Hoefer, Tome premier. Paris: Charpentier.

Estrabón (1992). Geografía. Libros III-IV. Trad. de M. J. Meana Cubero y F. Piñero Torre. Biblioteca Clásica Gredos, 169. Madrid: Gredos.

Severo de Menorca (1981). Epistula de conuersione Iudaeorum apud Minorcam insulam meritis sancti Stephani facta. Estudio preliminar de E. Lafuente Hernández. Mahón: Nura.

\section{BIBLIOGRAFÍA}

Aguelo, X., De Juan, C., Palomo, A. y Dehesa, R. (2011). "Prospección arqueológica del puerto de Ciutadella (Ciutadella, Menorca)". En: Nieto, X. (Coord.). Actas de las Jornadas del ARQUA (Cartagena, 2011). Madrid: Ministerio de Educación, Cultura y Deporte, pp. 24-30.

Anglada, M., Ferrer, A., Plantalamor, L., Ramis, D. y Van Strydonck, M. (2012). “Arquitectura monumental y complejidad social a partir de finales del segundo milenio cal BC: el Edificio Sur del sector oeste de Cornia Nou (Menorca)". Sardinia, Corsica et Baleares Antiquae, X, pp. 23-44.

Arribas, A., Tarradell, M. y Woods, D. E. (1973). Pollentia I. Excavaciones en Sa Portella, Alcudia (Mallorca). Excavaciones Arqueológicas en España, 75. Madrid: Ministerio de Cultura.

Ayán, X. (2003). "Arquitectura como tecnología de construcción de la realidad social". Arqueología de la Arquitectura, 2, pp. 17-24.

DOI: https://doi.org/10.3989/arq.arqt.2003.20

Blake, E. (1998). "Sardinia's nuraghi: four millennia of becoming". World Archaeology, 30, pp. 59-71. DOI: https://doi.org/10.1080/00438243.1998.9980397 
Calvo, M. (2009). "Reflexiones en torno a los esquemas de racionalidad espacial reflejados en el paisaje durante la Prehistoria de Mallorca". Pyrenae, 40 (2), pp. 37-78.

Calvo, M. y García, J. (2019). "Mirándonos al espejo: narrativas sobre el proceso colonial en la isla de Mallorca durante la Edad del Hierro (850-123 a.C.)". Pyrenae 50 (1), pp. 55-83. DOI: https://doi.org/10.1344/pyrenae2019.vol50num1.3

Carbonell, M. (2012). El Cercle 7 de Torre d'en Galmés. Estudi d'una estructura domèstica del segle III aC a Menorca. Trabajo fin de master. Barcelona: Universitat de Barcelona.

Carbonell, M., Corral, B., Ferrer, A., Lara, C., Pons, J., Riudavets, I. y De Salort, C. (2015). "Les excavacions arqueològiques al pati davanter del Cercle 7”. En: Martínez, A. y Graziani, G. (Coords.). VI Jornades d'Arqueologia de les Illes Balears (Formentera, 2014). Sant Francesc Xavier: Consell Insular de Formentera, pp. 91-100.

Carbonell, S. (2017). "Avance en la investigación del mundo funerario postalayótico menorquín en el marco del Proyecto Modular: hipogeos y problemática de estudio". En: Anglada, M., Riera, M. y Martínez, A. (Coords.). VII Jornades d'Arqueologia de les Illes Balears (Maó, 2016). Maó: Consell Insular de Menorca, pp. 173-178.

Cartailhac, É. (1892). Monuments primitifs des îles Baléares. Toulouse: Librairie Édouard Privat.

Castrillo, M. (2005). "Fenicis i púnics a Menorca: vint-icinc anys d'investigació i noves dades aportades per les àmfores feniciopúniques a l'illa". En: Ramon, J. (Coord.). Fenicis i púnics als Països Catalans. Fonaments, 12. Barcelona: Universitat de Barcelona, pp. 149-168.

Cau, M. A. y Chávez, M. E. (2003). "El fenómeno urbano en Mallorca en época romana: los ejemplos de Pollentia y Palma". Mayurqa, 29, pp. 27-49.

Cherry, J. F. y Leppard, T. P. (2018). "The Balearic Paradox: Why Were the Islands Colonized So Late?". Pyrenae, 49 (1), pp. 49-70.

Criado, F. (1993). "Límites y posibilidades de la Arqueología del paisaje". SPAL, 2, pp. 9-55.

DOI: https://doi.org/10.12795/spal.1993.i2.01

De Álvaro, E. (1983). “Análisis espacial de los poblados talayóticos en la isla de Menorca". En: Homenaje al prof. Martín Almagro Basch (vol. II). Madrid: Ministerio de Cultura, pp. 193-203.

De Cet, M. (2017). Long-term social development on a Mediterranean island: Menorca between 1600 BCE and $1900 C E$. Universitätsforschungen zur prähistorischen Archäologie Band 303. Human Development in Landscapes, 10. Bonn: Rudolf Habelt GmbH.

De Cet, M., Gornés, S., Gual, J., Müller, J., Sintes, E., Risch, R. y Willié, B. (2014). "Changing Settlement Patterns in the Mediterranean Context: a Case Study of Menorca (Balearic Islands) from Prehistory to the 19th Century AD”. En: Graeme, E., Sly, T., Chrysanthi, A., Murrieta-Flores, P., Papadopoulos, C., Romanowska, I. y Wheatley, D. (Eds.). Archaeology in the Digital Era. Papers from the 40th Annual Conference of Computer
Applications and Quantitative Methods in Archaeology (CAA), Southampton, 26-29 March 2012. Amsterdam: Amsterdam University Press, pp. 389-399.

De Nicolás, J. C. (1983). "Romanización de Menorca". En: Mascaró, J. (Coord.). Geografia e Historia de Menorca, tomo 4. Mahón: Consell Insular de Menorca, pp. 201284.

De Nicolás, J. C. (1995). El poblat talaiòtic de Son Catlar (tríptic-guia). Maó: Consell Insular de Menorca.

De Nicolás, J. C. (1997). "Casa prehistórica en el Aeropuerto de Menorca". Aena Arte, 3, pp. 46-49.

De Nicolás, J. C. (2003). "Els primers segles de l’ocupació romana de l'illa de Menorca: continuïtats i ruptures en l'àmbit rural'. Mayurqa, 29, pp. 111-128.

De Nicolás, J. C. (2015). “Aproximación a los cultos púnicos en las taulas menorquinas". En: Andreu, C., Ferrando, C. y Pons, O., eds., L'entreteixit del temps: miscel. lània d'estudis en homenatge a Lluís Plantalamor Massanet. Palma: Govern de les Illes Balears, pp. 265-284.

De Nicolás, J. C., Gornés, S. y Gual, J. M. (2017). “Indicis d'un santuari púnico-talaiòtic en el poblat de Biniparratx Petit (Sant Lluís, Menorca)”. En: Prados, F., Jiménez, H. y Martínez, J. J. (Coords.). Menorca entre fenicios y púnicos. Murcia: Publicaciones del CEPOAT 2 y Publicacions des Born 25, pp. 157-179.

De Nicolás, J. C. y Obrador, B. (2015). "Novetats epigràfiques menorquines I". Sylloge Epigraphica Barcinonensis, XIII, pp. 135-143.

Febvre, L. (1970). La Terre et l'évolution humaine. Introduction géographique a l'Histoire. Paris: Albin Michel.

Fentress, E. (2009). "Peopling the countryside: Roman demography in the Albegna Valley and Jerba". En: Bowman, A. y Wilson, A. (Eds.). Quantifying the roman economy. Methods and problems. Oxford Studies on the Roman Economy. Oxford: Oxford University Press, pp. 127-161.

Fernández-Miranda, M. (1976). "La fase final de la Prehistoria de Menorca y los primeros contactos comerciales de la isla con el mundo clásico". Revista de Menorca, 67, pp. 5-34.

Fernández-Miranda, M. (1991). "La transición hacia la cultura talayótica en Menorca". Trabajos de Prehistoria, 48, pp. 37-50. DOI: https://doi.org/10.3989/tp.1991.v48.i0.512

Fernández-Miranda, M. (2009). El poblado de Torralba d'en Salort (Alaior, Menorca). Mahón: Consell Insular de Menorca.

Fernández Ochoa, C., Salido, J. y Zarzalejos, M. (2014). "Las formas de ocupación rural en Hispania. Entre la terminología y la praxis arqueológica". Cuadernos de Prehistoria y Arqueología de la Universidad Autónoma de Madrid, 40, pp. 111-136. DOI: https://doi.org/10.15366/cupauam2014.40.008

Ferrer, A. (2010). "Les basses temporals i l'home". En: Fraga, P., Estaún, I. y Cardona, E. (Eds.). Basses temporals mediterrànies. Maó: Institut Menorquí d'Estudis, pp. 113-122. 
Flaquer, J. (1922). "Son Carlà". Revista de Menorca, 17, pp. 107-111.

Flaquer, J. (1952). “Alayor (Menorca). Torre d'en Gaumés. Excavaciones de 1943”. Noticiario Arqueológico Hispánico, pp. 110-120.

García Riaza, E. (2006). "Un aspecto de la práctica institucional en las comunidades indígenas hispanas: el control del espacio público". Cahiers du Centre Gustave Glotz, 17, pp. 175-185.

DOI: https://doi.org/10.3406/ccgg.2006.907

García Riaza, E. y Sánchez León, M. L. (2000). Roma y la municipalización de las Baleares. Palma de Mallorca: Edicions Universitat de les Illes Balears.

González-Ruibal, A. y Ruiz-Gálvez, M. L. (2016). "House Societies in the Ancient Mediterranean (2000-500 BC)". Journal of World Prehistory, 29, pp. 383-437. DOI: https://doi.org/10.1007/s10963-016-9098-8

Gornés, S. (1996). “Arqueología de la muerte y cambio social. Análisis e interpretación de la necrópolis de Cales Coves, Menorca". Complutum, 7, pp. 91-103.

Gornés, S., Gual, J. M., De Nicolás, J. C. y Roca, A. (2004). "L'asentament humà des de la prehistòria fins al baix imperi”. En: Fornós, J., Obrador, A. y Rosselló, V. M. (Eds.). Història Natural del Migjorn de Menorca: el medi fisic i l'influx humà. Es Migjorn: Societat d'Història Natural de les Balears, pp. 327-350.

Gornés, S., Guerrero, V. M., Hernández-Gasch, J., De Nicolás, J. C. y Van Strydonck, M. (2001). "La campanya de excavación de 2001 en Biniparratx Petit (Menorca). Avance de los primeros anàlisis radiocarbónicos". Mayurqa, 27, pp. 227-235.

Grau, I. (2006). La aplicación de los SIG en Arqueología. Alicante: Universidad de Alicante.

Grau, I., Carreras, C., Molina, J., De Soto, P. y Segura, J. M. (2012). "Propuestas metodológicas para el estudio del paisaje rural antiguo en el área central de la Contestania". Zephyrus, LXX (julio-diciembre), pp. 131-149.

Guerrero, V. M. (1990). "Problemas en torno al inicio de la Romanización en Mallorca”. Saguntum, 23, pp. 225-242.

Guerrero, V. M. (1997). La colonización púnica de Mallorca. La documentación arqueológica y el contexto histórico. Palma de Mallorca: El Tall.

Guerrero, V. M., Calvo, M. y Gornés, S. (2006). Historia de las Islas Baleares. Mallorca y Menorca en la Edad del Hierro. La cultura Talayótica y Postalayótica (vol. 2). Palma de Mallorca: El Mundo.

Guerrero, V. M., Calvo, M. y Salvà, B. (2002). "La cultura talayótica. Una sociedad de la Edad del Hierro en la periferia de la colonización fenicia”. Complutum, 13, pp. 221-258.

Gutiérrez, S. y Grau, I. (2013). De la estructura doméstica al espacio social. Lecturas arqueológicas del uso social del espacio. Alicante: Universidad de Alicante.

Hernández-Gasch, J. (2009). "Les illes Balears en época tardoarcaica”. En: Nieto, X. y Campos, M. (Eds.). El vaixell grec de cala Sant Vicenç. Girona: Monografies del CASC, pp. 273-292.

Hernández-Gasch, J. y Aramburu-Zabala, J. (2005). "Murallas de la Edad del Hierro en la Cultura Talayótica. El recinto fortificado del poblado de Ses Païses (Artà, Mallorca)". Trabajos de Prehistoria, 62 (2), pp. 125-149. DOI: https://doi.org/10.3989/tp.2005.v62.i2.72

Hernández Mora, J. (1923). "Menorca prehistórica II". Revista de Archivos, Bibliotecas y Museos, 27, pp. 1-33.

Hernández Mora, J. (1948). "Menorca prehistórica. Notas descriptivas". Revista de Menorca, 34, pp. 245-330.

Horden, P. y Purcell, N. (2000). The corrupting sea. A study of Mediterranean History. Oxford: Blackwell.

Icomos (2017). Talayotic Minorca (Spain) $n .^{\circ} 1528$. Paris: Icomos.

Ingold, T. (1993). "The Temporality of Landscape". World Archaeology, 25 (2), pp. 152-174. DOI: https://doi.org/10.1080/00438243.1993.9980235

Jiménez Vialás, H., León, M. J., Prados, F. y Torres, O. (2019). Son Catlar. Plan director. Investigación, difusión y puesta en valor. Mahón: Consell Insular de Menorca.

Jiménez Vialás, H., Prados, F., De Nicolás, J., Adroher, A. M. y Martínez, J. J. (2017). “Contextos cerámicos en Torrellafuda (Ciutadella, Menorca). Análisis de material de superficie”. En: Anglada, M., Riera, M y Martínez, A. (Coords.). VII Jornades d'Arqueología de les Illes Balears (Maó, 2016). Maó: Consell Insular de Menorca, pp. 161-172.

Jiménez Vialás, H., Prados, F., De Nicolás, J. C. y Adroher, A. M. (2021). "Punic amphorae from Minorca Island in Post-Talayotic period (4th to 1st century BC)". En: Martínez, V. (Ed.). 1st amphoras of the Phoenician-Punic World Congress. The state of the art (Gent, Belgium). Gent: Ancient Near Eastern Studies (e.p.).

Juan, G. (1993). El poblament de Menorca; de la Prehistòria a la baixa romanitat (aproximació a una proposta d'anàlisi de distribució espacial). Treballs del Museu de Menorca, 13. Maó: Museu de Menorca.

Juan, R., Pons, O. y Juan, Q. (1998). Poblat de Son Catlar. Memòria de la campanya Juny-Setembre de 1995. Ciutadella: informe de excavación arqueológica.

Knapp, A. B. (2007). "Insularity and island identity in the prehistoric Mediterranean”. En: Antoniadou, S. y Pace, A., eds., Mediterranean Crossroads. Athens: Pierides Foundation, pp. 37-62.

Kopper, J. S. y Rosselló-Bordoy, G. (1974). "Megalithic Quarrying Techniques and Limestone Technology in Eastern Spain". Journal of Field Archaeology, 1 (1-2), pp. 161-170. DOI: https://doi.org/10.2307/529711

Kouremenos, A. (ed.) (2017). Insularity and identity in the Roman Mediterranean. Oxford: Oxbow Books.

Llull, B., Perelló, L., Guerrero, V. M., Fullola, J. M., Petit, M. Á. y Calvo, M. (2019). "Caracterización isotópica y elemental de los metales de Cova des Pas (Ferreries, Menorca). Una necrópolis de transición del Bronce Final al Hierro". Trabajos de Prehistoria, 76 (1), pp. 102-119. DOI: https://doi.org/10.3989/tp.2019.12228

Lull, V., Micó, R., Rihuete, C. y Risch, R. (2001). La prehistòria de les Illes Balears i el jaciment arqueologic de Son Fornés (Montuïri, Mallorca). Montuïri: Edicions de Son Fornés.

Martín, A., De Nicolás, J. C., Riera, M. y Salvà, B. (2020). "Lingots d'estany romans trobats a l'aigua de la costa sudoest de Menorca". En: Hernández-Gasch, J., Rivas, M.J, y Rivas, M. (Coords.). VIII Jornades d'Arqueologia de les 
Illes Balears (Alcúdia, 2018). Alcúdia: Consell Insular de Mallorca, pp. 289-298.

Martínez Santa-Olalla, J. (1924). "La cerámica pintada ibérica en Menorca". Revista de Menorca, 19, pp. 121-129.

Mascaró, J. (1982). Carta arqueológica de Menorca. Mahón: Consell Insular de Menorca.

Mattingly, D. (1983). "Roman Pollentia: coinage and history". En: Arribas, A. (Ed.). Pollentia. Estudio de los materiales I: Sa Portella, excavaciones 1957-1963. William L. Bryant Foundation, 3. Palma de Mallorca: Bryant Foundation, pp. 243-301.

Mayer, M. (2005). "Les Illes Balears i llur reflex a les fonts literàries i epigràfiques. Revisió d'alguns aspectes". En: Sánchez, M. L. y Barceló, M. (Eds.). L’Antiguitat clàssica i la seva pervivència a les Illes Balears (Actes de les XXIII Jornades d'Estudis Històrics Locals). Palma: Institut d'Estudis Baleàrics, pp. 29-60.

Mayoral, V., Cerrillo, E. y Celestino, S. (2009). "Métodos de prospección arqueológica intensiva en el marco de un proyecto regional: el caso de la comarca de La Serena (Badajoz)". Trabajos de Prehistoria, 66 (1), pp. 7-25. DOI: https://doi.org/10.3989/tp.2009.09010

Micó, R. (2005). Cronología absoluta y periodización de las islas Baleares. BAR International Series 1373. Oxford: Archaeopress.

Navarro, F. J. (2004). Excavaciones arqueológicas en el yacimiento de "Ses Talaies de n'Alzina". Poblado talayótico afectado por las obras de la ronda Norte (Ciutadella). Mahón: Consell Insular de Menorca.

Óleo y Quadrado, R. (1874). Historia de la isla de Menorca. Ciudadela: S. Fábregues.

Orfila, M. (1988). La necrópolis de Sa Carrotja y la romanización del sur de la isla de Mallorca. BAR International Series, 397. Oxford: Archaeopress.

Orfila, M. (2008). "La intervención de Q. Cecilio Metelo sobre las Baleares (123 a 121 a.C.). Condiciones previas y sus consecuencias". Pyrenae, 39 (2), pp. 7-45.

Orfila, M., Arribas, A. y Cau, M. A. (1999). "La ciudad romana de Pollentia: el foro". Archivo Español de Arqueologia, 72 (179-180), pp. 99-118.

DOI: https://doi.org/10.3989/aespa.1999.v72.298

Orfila, M., Chávez, M. E. y Cau, M. A. (2006). "Pollentia and the cities of the Balearic Islands". En: Abad, L., Keay, S. y Ramallo, S. (Eds.). Early Roman Towns in Hispania Tarraconensis. Journal of Roman Archaeology Supplementary Series, 62. Rhode Island: Oxbow Books, pp. 133-145.

Orfila, M. y Riera, M. (2004). "Les ciutats romanes de Menorca (ss. II aC - V dC)". En: Orfila, M. y Cau, M. A. (Coords.). Les ciutats romanes del llevant peninsular $i$ les Illes Balears. Barcelona: Pòrtic, pp. 239-260.

Orfila, M., Sánchez, E., Gutiérrez, M. y Marín, P. (2017). "Religio Balearica. La continuidad cultual de los santuarios talayóticos en época romana". En: Tortosa, T. y Ramallo, S. (Eds.). El tiempo final de los santuarios ibéricos en los procesos de impacto y consolidación del mundo romano. Anejos de Archivo Español de Arqueología, LXXIX. Madrid: Editorial CSIC, pp. 213-230.
Orfila, M. y Sintes, G. (1984). "Estudio preliminar sobre la perduración del hábitat en los conjuntos talayóticos menorquines". Mayurqa, 20 (1981-1984), pp. 19-46.

Pérez-Juez, A. (2012). "La exposición monográfica 'Manurqa'. Proyecto didáctico de Boston University sobre la excavación de una estructura andalusí en Torre d'en Galmés". En: Riera, M. (Ed.). IV Jornades d'Arqueologia de les Illes Balears (Eivissa, 2010). Eivissa: Consell Insular d'Eivissa, pp. 179-186.

Pérez-Juez, A. y Goldberg, P. (2018). "Evidence of Quarrying at the Iron Age Site of Torre d'en Galmés, Menorca, Spain”. Boletín Geológico y Minero, 129 (1/2), pp. 353-370.

Pericot, L. (1975). Las islas Baleares en los tiempos prehistóricos. Barcelona: Destino.

Plantalamor, L. (1991). L'Arquitectura prehistòrica i protohistòrica de Menorca i el seu marc cultural. Treballs del Museu de Menorca, 12. Maó: Museu de Menorca.

Plantalamor, L. y Rita, M. C. (1982). "Tres cuevas de la Edad del Bronce en la zona occidental de Menorca". Ampurias, 44, pp. 1-16.

Pons Machado, O. (2012). "Materials púnics trobats al litoral de Menorca”. En: Riera, M. (Ed.). IV Jornades d'Arqueologia de les Illes Balears (Eivissa, 2010). Eivissa: Consell Insular d'Eivissa, pp. 99-104.

Pons Machado, J. (2016). Caracterització de l'espai de l'hàbitat protohistòric de l'illa de Menorca: les cases de planta circular talaiòtiques. Tesis doctoral. Barcelona: Universitat Autònoma de Barcelona.

Prados, F., De Nicolás, J. C., Jiménez, H., Martínez, J. J. y Torres, O. (2015). "Culturas arquitectónicas púnicas. Menorca como laboratorio de análisis". En: Martínez, A. y Graziani, G. (Coords.). VI Jornades d'Arqueologia de les Illes Balears (Formentera, 2014). Sant Francesc Xavier: Consell Insular de Formentera, pp. 185-192.

Prados, F. y Jiménez, H. (2017). "Menorca entre fenicios y púnicos: una aproximación arqueológica desde la arquitectura defensiva”. En: Prados, F., Jiménez, H. y Martínez, J. J. (Coords.). Menorca entre fenicios y púnicos. Murcia: Publicaciones del CEPOAT 2 y Publicacions des Born 25, pp. 107-138.

Prados, F., Jiménez, H. y García, J. J. (Coords.) (2017). Menorca entre fenicios y púnicos. Murcia: Publicaciones del CEPOAT 2 y Publicacions des Born 25.

Prados, F., Jiménez, H., León, M. J., Adroher, A. M., De Nicolás, J. y Martínez, J. J. (2017a). "Menorca entre Cartago y Roma: avance de la excavación arqueológica del proyecto Modular en el poblado de Son Catlar (Ciutadella)". En: Anglada, M., Riera, M. y Martínez, A. (Coords.). VII Jornades d'Arqueologia de les Illes Balears (Maó, 2016). Maó: Consell Insular de Menorca, pp. 153-160.

Prados, F., Jiménez, H., León, M. J., De Nicolás, J. C., Adroher, A. M. y Torres, O. (2020). "Entre Cartago y Roma. Son Catlar y el impacto púnico en Menorca". En: Celestino, S. y Rodríguez, E. (Eds.). IX Congreso Internacional de Estudios Fenicios y Púnicos. MYTRA, 5. Mérida: CSIC, pp. 1539-1549. 
Prados, F., León, M. J., Jiménez, H., Adroher, A. M., Torres, O., De Nicolás, J. C. y Carbonell, S. (2017b). Proyecto Modular. Análisis arqueológico y documental de la arquitectura fenicio-púnica de Menorca. Informe-memoria de la actuación arqueológica en el poblado de Son Catlar (Ciutadella) 2016. Original depositado en el Consell Insular de Menorca.

Puig Palerm, A. (2014). "La piratería en el archipiélago balear en la Antigüedad ¿sólo una causa de la intervención romana del 123 a.C.?”. En: Álvarez-Ossorio, A., Ferrer E. y García, E. (Coords.). Piratería y seguridad marítima en el Mediterráneo antiguo. SPAL Monografías, XVII. Sevilla: Universidad de Sevilla, pp. 145-166.

Quintana, C. y Guerrero, V. M. (2005). "La colonització púnica de Mallorca. Balanç d'un quart de segle d'investigació”. En: Ramon, J. (Coord.). Fenicis i púnics als Països Catalans. Fonaments, 12. Barcelona: Universitat de Barcelona, pp. 139-148.

Ramis, D. (2017). "La arquitectura monumental en los inicios de la cultura talaiótica”. En: Moravetti, A., Melis, P., Foddai, L. y Alba, E. (Eds.). La Sardegna Nuragica. Storia e monumento. Sassari: Carlo Delfino Editore, pp. 191-209.

Ramis y Ramis, J. (1818). Antigüedades célticas de la Isla de Menorca desde los tiempos más remotos hasta el siglo IV de la Era Cristiana. Mahón: Imprenta Pedro Antonio Serra.

Ramon, J. (2007). Excavaciones arqueológicas en el asentamiento fenicio de sa Caleta (Ibiza), Cuadernos de Arqueología Mediterránea, 16. Barcelona: Bellaterra.

Ramon, J. (2017). "Pecios y ¿colonias? Materiales púnicos en las Islas Baleares". En: Prados, F., Jiménez, H. y Martínez, J. J. (Coords.). Menorca entre fenicios y púnicos. Murcia: Publicaciones del CEPOAT 2 y Publicacions des Born 25, pp. 41-84.

Rosselló-Bordoy, G. (1963). "Una aproximación a la Prehistoria de Mallorca”. Ampurias, XXV, pp. 137-163.

Rosselló-Bordoy, G. (1972). "La prehistoria de Mallorca. Rectificaciones y nuevos enfoques al problema". Mayur$q a$, VII, pp. 115-156.

Sánchez León, M. L. (2003). "La ciudad de Mago (Maó, Menorca): continuidades y rupturas". Mayurqa, 29, pp. 97-109.

Sánchez López, E., Orfila, M., Gutiérrez, M. y Marín, P. (2016). "La Cova dels Jurats de Calescoves (Alaior, Menorca). ¿Un santuario rupestre en el mundo Talayótico?”. Complutum, 27 (1), pp. 185-198. DOI: https://doi.org/10.5209/cmpl.53222

Serra, M. L. (1961). "De arqueología menorquina: círculos". Revista de Menorca, Cuaderno II (Octubre-Diciembre), pp. 65-74.

Serra, M. L. (1963). "Canteras y pozos prehistóricos en Menorca”. Ampurias, XXV, pp. 186-192.

Serra, M. L. (1965). "Arquitectura ciclópea menorquina". En: Pericot, L. (Ed.). Coloquio sobre Arquitectura me- galítica y ciclópea catalano-balear (24-26 abril 1965). Barcelona: CSIC, pp. 151-172.

Serra, M. L. (1967). X Congreso Nacional de Arqueología. Segunda circular, programa y guía. Mahón: Ayuntamiento de Mahón.

Simón, M., Armentano, N., Afonso, C. y Malgosa, A. (2016). "La Menorca talayótica desde el punto de vista genético: la necrópolis de la Cova des Pas". Trabajos de Prehistoria, 73 (2), pp. 335-351.

DOI: https://doi.org/10.3989/tp.2016.12178

Sintes, E. e Isbert, F. (2009). "Investigación arqueológica y puesta en valor del Recinto Cartailhac. Una unidad doméstica del siglo II ANE en el poblado talayótico de Torre d'en Galmès". Patrimonio Cultural de España, 1, pp. 251-258.

Sintes, E. y León, M. J. (2019). Que la terra et sigui lleu. Una història de la mort a Menorca, Maó: Consell Insular de Menorca.

Tarradell, M. (1983). "La romanització de Mallorca: alguns aspectes i un problema". En: Symposium de Arqueología Pollentia y la Romanización de las Baleares: XXI Centenario de la Fundación de Pollentia (Alcudia, 1977). Alcúdia: Ajuntament d'Alcúdia, pp. 123-128.

Thomas, J. (2001). "Archaeologies of place and landscape". En: Hodder, I. (Ed.). Archaeological Theory Today. Malden: Polity Press, pp. 165-186.

Tilley, C. (1994). A Phenomenology of Landscape. Places, paths and monuments. Oxford: Berg.

Torres Bagur, A., Obrador, B. y De Nicolás, J. C. (2017). “'Baal-Hammon', 'Caelestis' y el dios del plenilunio en el santuario con taula de Son Catlar (Ciutadella de Menorca)". En: Prados, F., Jiménez, H. y Martínez, J. J. (Coords.). Menorca entre fenicios y púnicos. Murcia: Publicaciones del CEPOAT 2 y Publicacions des Born 25 , pp. 245-275.

Torres Gomariz, O. (2016). "De arqueología menorquina: Maria Lluïsa Serra Belabre y los círculos talayóticos de Sant Vicenç d'Alcaidús (Alaior, Menorca)", Panta Rei, 2016, 19-36. DOI: https://doi.org/10.6018/pantarei/2016/2

Valenzuela, A., Alcover, J. A. y Cau, M. A. (2017). “The impact of Roman conquest on the pattern of livestock exploitation on the Balearic Islands". Archaeofauna, 26, pp. 127-142.

DOI: https://doi.org/10.15366/archaeofauna2017.26.009

Veny, C. (1965). Corpus de las inscripciones baleáricas hasta la dominación árabe. Biblioteca de la Escuela Española de Historia y Arqueología en Roma, 15. Roma: CSIC.

Vives Escudero, A. (1908). "El arte egeo en España”. Cultura Española, 12 (11), pp. 1033-1063.

Zucca, R. (1998). Insulae Baliares: Le Isole Baleari sotto il dominio romano. Sassari: Carocci. 